\title{
Shear Strengthening of Damaged Reinforced Concrete Beams with Hybrid Composite Plates
}

\author{
Hadi Baghi ${ }^{1}$, Joaquim A. O. Barros ${ }^{2}$, Mohammadali Rezazadeh ${ }^{3}$
}

1- Post-Doc, Civil Engineering and Construction Engineering Technology, Louisiana Tech University, Ruston, U.S. (corresponding author) e-mail: hadibaghi@gmail.com

2- Full Professor, ISISE, Department of Civil Engineering, University of Minho, Guimarães, Portugal, e-mail: barros@civil.uminho.pt

3- Post-Doc, ISISE, Department of Civil Engineering, University of Minho, Guimarães, Portugal, e-mail: rzh.moh@gmail.com

\begin{abstract}
This paper aims to evaluate experimentally the potentialities of Hybrid Composite Plates (HCPs) technique for the shear strengthening and repairing of reinforced concrete (RC) beams. HCP is a thin plate of Strain Hardening Cementitious Composite (SHCC) reinforced with Carbon Fiber Reinforced Polymer (CFRP) laminates. For this purpose, an experimental program composed of four Rectangular and five T-cross section beams was executed to assess the strengthening efficiency of HCPs technique. There were two control beams without any type of shear reinforcement, and seven beams strengthened with HCPs. The HCPs were applied to the lateral faces of the beams by using a combination of epoxy adhesive and mechanical anchors. The bolts were applied with a certain torque in order to increase the concrete confinement. To have a better understanding of the shear behavior of SHCC material, Iosipescu shear tests were carried out, and the results were used to derive their fracture mode II parameters.

To further explore the potentialities of the HCPs technique for the shear strengthening, the experimental tests were simulated numerically by a FEM-based computer program considering the material properties obtained experimentally. After demonstration of the good predictive performance of the numerical model, a parametric study was executed to investigate the influence of some parameters on the load carrying capacity of the strengthened beams, namely: i) Use a mortar instead of the SHCC; ii) application of different applied torque level to the mechanical anchors; iii) different bond condition between HCPs and concrete substrate.
\end{abstract}

Keywords: Strain Hardening Cementitious Composites; Near Surface Mounted; CFRP laminates; Shear Strengthening; Iosipescu Shear Test; Finite Element Method; 


\section{Introduction:}

Reinforced Concrete (RC) structures often require repair and strengthening due to alterations on the load or support conditions, deterioration of the materials, or structural damage caused by earthquake or extreme loading events. There are many different techniques and materials for repairing or strengthening of RC structures such as: externally bonded steel plates [1], embedded through section (ETS) [2], or fiber reinforced polymers (FRP) [3].

Difficulty to manipulate the steel plates at the construction site due to their weight, and also durability concerns associated with a reduction in the bond between steel plates surface and adhesive, as well as corrosion susceptibility, are disadvantages of externally bonded steel plates [1,4]. Finding the position of the longitudinal steel bars, get enough space to make the holes through section, and the difficulty of executing the holes with the optimized inclination are some drawbacks of ETS technique.

FRP materials are used for shear strengthening of RC beams, by adopting the following techniques: externally bonded reinforcement (EBR); near surface mounted (NSM). These techniques have been extensively investigated and applied in structural strengthening due to several advantages, namely, high strength and stiffness to weight ratio, flexibility, and easy installation [5-9].

Al-Sulaimani et al. [10] tested RC beams strengthened with external glass FRP plate. The obtained results showed that the proposed GFRP-bonding schemes can increase the shear capacity and stiffness of shear damaged RC beams. In a study conducted by Alzoubi et al. [11], a technique based on the use of CFRP strips for the repair of pre-damaged RC beams was investigated. The load carrying capacity of the repaired beams was about $95 \%$ of the corresponding beams in undamaged state. Jayaprakash et al. [12] used bi-directional CFRP strips for the shear strengthening of precracked rectangular cross section RC beams, and an increase of $13 \%$ in the shear capacity was obtained when compared to the corresponding undamaged beams. Dirar et al. [13] investigated the behaviour of pre-cracked T-cross section RC beams shear strengthened with prestressed CFRP strips. The results shown an enhancement of $22 \%$ to $46 \%$ in the shear capacity when compared to the corresponding one of the unstrengthened beams.

Based on the results in the literature $[7,8,11,14,15]$, it is not appropriate to use the EBR and NSM when the quality of concrete cover is too low or the thickness of the concrete cover is too small for the installation of the NSM-FRP systems. When shear stirrups are too susceptible to corrosion due to deficient resistance of concrete cover to the propagation of carbonation, EBR and NSM systems are also not appropriate strengthening solutions. 
Strain Hardening Cementitious Composite (SHCC) can be the support material for the FRP reinforcements in order to constitute an effective strengthening solution that can be fixed to concrete structures with anchorage systems. Recently, SHCC was used to produce thin plates to increase the shear capacity of RC beams [16]. Reinforced SHCC exhibits ductile shear response, high energy absorption capacity, stable hysteretic loops even at large drifts, and structural integrity [17-19].

Recently, Hybrid Composite Plates (HCPs) have been used to increase the load carrying capacity, energy dissipation, hysteretic response, and ductility behavior of the RC elements. HCP is formed by a thin plate of SHCC (around 20 $\mathrm{mm}$ ) that is reinforced by CFRP laminates [16] according to the procedures adopted in the NSM technique [20]. To bond the CFRP laminates into the SHCC plate, slits of a width and a depth of about $4 \mathrm{~mm}$ and $11 \mathrm{~mm}$, respectively, are opened on the surface of the plate, and CFRP laminates are inserted into these slits and bonded to the surrounding SHCC with an appropriate epoxy adhesive. The prefabricated HCPs can be bonded to the lateral faces of the beams using epoxy adhesive and mechanical anchors. A schematic view of this technique is presented in Figure 1.

Due to the excellent bond conditions between SHCC plate and CFRP laminates, these reinforcements provide the necessary tensile strength capacity to the HCP. Moreover, the high post-cracking tensile deformability and resistance of SHCC avoid the occurrence of premature fracture failure of this cement composite in the stress transfer process between these two materials when the HCP is crossed by a shear crack. The mechanical anchors prevent premature debonding of the HCPs, and provide a certain level of concrete confinement in the strengthened zone of the beam, leading to favorable effects in terms of shear strengthening effectiveness. Besides the contribution of the SHCC for the strengthening efficiency of HCPs, the SHCC also assures some protection to the CFRP laminates and adhesive with respect to accidental actions, such as vandalism, aggressive environmental conditions, and fire [21].

For assessing the behaviour of SHCC in shear, a test setup capable of introducing a uniform shear stress field is required. Several shear test setup configurations have been proposed by various researchers [22-26], being the Iosipescu shear test considered the most appropriate for composite materials [27]. The Iosipescu test specimens are loaded in antisymmetric four point bending with a double notch in the region with highest shear force and null bending moment, which creates a section of pure shear and a uniform shear stress distribution in the reduced section (Figure 2).

In the present work, the influence of the HCP on shear strengthening/repairing of RC beams is investigated by executing an experimental program. The experimental program was composed of rectangular and $\mathrm{T}$ cross section RC 
beams. In the first step of this experimental program, the control beams (without any shear reinforcement) were loaded up to their failure, and then fully unloaded. In the next step, the damaged beams were repaired by applying the HCPs to lateral faces of the beam in the damaged zone. The HCPs were bonded using epoxy adhesive, and fixed by mechanical anchors. The experimental program is detailed and the obtained results are presented and discussed. Advanced numerical simulations were carried out to contribute for a better understanding of the effectiveness of the shear strengthening technique with HCPs. The values of the fracture mode II parameters of the SHCC (crack shear strength and fracture energy) used in this study were obtained by simulating the Iosipescu shear tests. A good predictive performance in terms of the deformational response and crack pattern was obtained in the numerical simulations of the tested beams.

A parametric study was carried out to investigate the influence of the several technological aspects of the HCPs technique on the beam's load carrying capacity, namely: 1) the fracture energy of the cement based material forming the strengthening panel (plain mortar versus SHCC); 2) level of applied torque to the mechanical anchors; 3) the use, or not, of an adhesive for assuring perfect bond of the HCPs to the concrete surface.

\section{Experimental program:}

\section{Test Matrix}

As shown in Figure 3, the experimental program was formed by two series of beams, the series A of rectangular cross section beams, while the series B of T cross section beams. The longitudinal reinforcement of series A was formed by $2 \phi 20$ at bottom and $2 \phi 10$ at top, while in series B was composed by $2 \phi 32$ and $1 \phi 16$ at bottom and $6 \phi 12$ at top. To localize shear failure in only one span, a three point bending test setup of different span length was adopted. In series A and B the length of monitored shear span, $a$, was 3.0 and 2.5 times the effective beam's depth, $d$, respectively. A relatively high shear reinforcement was applied in the other span $\left(L_{r}\right)$ for avoiding shear failure in this span ( $\phi 8 @ 100$ $\mathrm{mm}$ in series $\mathrm{A}$ and $\phi 6 @ 75 \mathrm{~mm}$ in series $\mathrm{B})$.

The reference shear reinforced beam (Type 1) of series A and series B had $\phi 8 @ 100$ and $\phi 6 @ 112.5$ steel shear reinforcement in monitored shear span, while the other beams of both series (Type 2) did not include steel stirrups in $L_{i}$ shear span.

The characteristics of the beams are presented in Table 1. To distinguish between the strengthened beams, the R/T-DNL-B/BC designation was adopted, where R/T means a rectangular or $\mathrm{T}$ cross section beam, $\mathrm{D}$ (when existing) 
indicates a damaged beam, $\mathrm{N}$ means the number of the CFRP laminates (L) in the HCP, B indicates that the HCP was bonded and anchored, and BC in case of also including connectors in the web-flange. The R-7S-R and T-7S-R are the

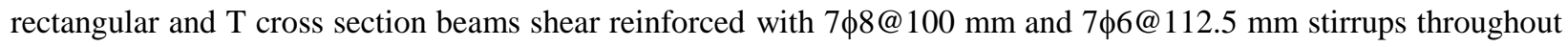
the monitored shear span, respectively. The R-C-R and T-C-R were control beams without shear reinforcement throughout the $L_{i}$ span. These control beams were initially loaded up to their shear failure load, and then fully unloaded. In the next step these beams were repaired by applying HCPs to each lateral face of the monitored shear span using a combination of epoxy adhesive and mechanical anchors. The repaired beams, designated by R-D-3L-B and T-D-5L-BC, were subjected to the same test configuration adopted in their virgin state. The HCP in this experimental program was a SHCC plate of $20 \mathrm{~mm}$ thick that was reinforced with CFRP laminates at $45^{\circ}$. The R-3L, T-5L-B, and T-5L-BC were beams strengthened with HCPs to upgrade their shear capacity. When HCPs ensure a quite significant increase of shear capacity, failure can occur at web/flange interface due to the strengthening discontinuity at this interface. To avoid this type of failure mode, and better mobilize the shear strengthening capabilities of HCPs, the T-5L-BC and T-D-5L-BC beams were also strengthened with 4 steel bars connectors (Figure 4).

The load was applied by using a servo closed loop equipment, taking the signal in the displacement transducer (LVDT) of the servo-actuator to control the test at a deflection rate of $0.01 \mathrm{~mm} / \mathrm{s}$. The deflections of the beams at loaded section and at mid-span were measured by two LVDTs that were supported on an aluminum bar fixed at the alignments of the supports of the beams in order to register exclusively the beam's deflection. With the purpose of obtaining the strain variation in the laminates, strain gages were bonded to the CFRP laminates according to the arrangement represented in Figure 4.

The main characteristics of the materials used in this experimental program are presented in Tables 2 and 3 . The concrete compressive strength was determined according to EN-206-1 [28]. To assess the tensile behavior of the steel bars, uniaxial tensile tests were carried out according to EN10002-1 recommendations [29]. The tensile properties of the CFRP laminates and epoxy adhesive were characterized by executing uniaxial tensile tests according to the recommendations of ISO 527-5 [30] and ISO 527-2 [31], respectively. The mix composition, curing process and experimental characterization of the SHCC are detailed in [16]. 


\section{Strengthening Techniques}

To apply the HCPs to the lateral faces of the concrete beams on the monitored shear span, the following procedures were executed: 1) in the R-3L, T-5L-B, and T-5L-BC beams a 1-2 mm roughness with sandblast was executed in the concrete substrate to improve the bond conditions between the HCPs and the concrete; 2) in the R-D-3L-B, T-5L-B, T-5L-BC, and T-D-5L-BC beams holes were drilled through web of the beam with a diameter of $12 \mathrm{~mm}$ for the installation of mechanical anchors as illustrated in Figure 4; 3) an epoxy adhesive (S\&P220) layer of a thickness of about $1 \mathrm{~mm}$ was homogenously applied on the surfaces of the concrete beam and on the HCP surface that will be in contact; 5) in the R-3L beam mechanical clamps were used to maintain the HPCs pressed against the lateral surfaces of the beam up to the time that the epoxy resin developed almost its full strength capacity (approximately 2 days); 6 ) in the R-D-3L-B, T-5L-B, T-5L-BC, and T-D-5L-BC beams the HCPs were also fixed to the concrete substrate of these beams with mechanical fasteners composed of bolts and nuts, by applying a torque of 20 N.m in the nuts on both sides of the beams.

In the R-D-3L-B and T-D-5L-BC beams the disposition of the CFRP laminates and mechanical anchors and in the TD-5L-BC beam the arrangement of mechanical anchors were designed in an attempt of assuring to the HCP the highest resistance to the opening and sliding of existing shear failure crack in the beams to be strengthened (Figures $4 \mathrm{~b}$ and 4e). Accordingly, these arrangements depend on the geometry of these cracks. It should be noticed that no repairing material was used for sealing the existing cracks in the R-D-3L-B and T-D-5L-BC beams.

For offering resistance to the propagation of cracks through the web-flange interface of the strengthened beams (just above the top border of the HCPs), four $\phi 10$ steel bars of $200 \mathrm{~mm}$ length were applied in the T-5L-BC and T-D-5L$\mathrm{BC}$ beams, as shown in Figures 4d and 4e, respectively. For this purpose, holes of $12 \mathrm{~mm}$ were opened in the flange of the beam, in the alignment coinciding with the middle surface of the concrete cover thickness of the lateral faces of the beams. The holes were cleaned by compressed air. Sikadur 32 adhesive was prepared according to supplier recommendations, and the bars were introduced into the holes that were previously filled with this adhesive. A period of 7 days was dedicated to cure the adhesive prior to testing these beams. 


\section{Results of the tested beams:}

\section{Load carrying capacity of the tested beams}

The relationship between load and deflection at loaded section of the beams are shown in Figures $5 \mathrm{a}$ and $5 \mathrm{~b}$. The maximum load and its corresponding deflection of the tested beams are presented in Table 4. The values of the $F_{\max } / F_{\max }^{7 S-R}$ ratio are also presented in Table 4 , which is the ratio between the maximum load capacity of the beam strengthened with HCPs $\left(F_{\max }\right)$ and its corresponding value in the beam shear reinforced with seven steel stirrups (

$\left.F_{\max }^{7 S-R}\right)$. The results demonstrate that the use of HCP is an effective technique to increase the shear capacity of the RC beam with and without damage. These results also reveal that the maximum load carrying capacity of the shear strengthened rectangular beams, with and without damage (R-D-3L-B and R-3L), was $88 \%$ and $91 \%$ of the corresponding beam with a steel shear reinforcement ratio of $0.66 \%$ (R-7S-R).

The shear capacity of the $\mathrm{T}$ cross section shear strengthened beam without steel shear connectors in the web-flange interface (T-5L-B) was $68 \%$ of the corresponding beam with a steel shear reinforcement ratio of $0.28 \%$ (T-7S-R). Adding this type of steel shear connector bars, the shear capacity of the beam with (T-D-5L-BC) and without damage (T-5L-BC) was $100 \%$ and $104 \%$ of the T-7S-R beam, respectively.

In the post peak stage, the load of T-5L-B beam was decreased smoothly and stabilized at a level of $55 \%$ of the maximum load. This is justified by the extra contribution of the aggregate interlock resisting mechanisms along a relatively large length of the failure crack, which has an irregular shape caused by its propagation through the top and lateral boundaries of the HCP.

As shown in Figure 5b, T-7S-R beam failed with an abrupt load decay, and then the load was stabilized at a level of about $100 \mathrm{kN}$ (19\% of maximum load), which almost corresponds to the shear resistance assured by the longitudinal bars due to dowel effect, obtained according to the CEB-FIP Model Code 2010 [32].

\section{Failure modes}

The failure mode of the rectangular and T cross section is presented in Figures 6 and 7, respectively. The R-C-R and T-C-R beams had no steel stirrups throughout the monitored shear span. In the R-C-R beam, at a load level of about $61 \mathrm{kN}$ three cracks became visible. By increasing the load, one of these cracks degenerated in the shear failure crack, while the other two cracks entered in a closing process. This beam failed in shear with an abrupt load decay after the peak load. In T-C-R beam two crack became visible at a load of about $100 \mathrm{kN}$. One crack initiated at the support 
section (splitting crack), and the other one formed at the center of the shear span. By increasing the load, these cracks widened and propagated up to load of $214 \mathrm{kN}$. At this load level the beam failed at the support section before shear failure of the beam has occurred (Figure 7a). This failure mode was not expected and was caused by a deficient execution of the anchorage arrangement of the longitudinal reinforcement. As shown in Figure 7a by a red ellipse, at a load of $214 \mathrm{kN}$ the critical shear crack formed, and it did not degenerate in a shear failure crack due to the unexpected splitting failure crack at the support of the beam in consequence of to the aforementioned reasons. The numerical simulation of the response of this beam has predicted the occurrence of a shear failure at a load of $215 \mathrm{kN}$.

As shown in Figure 3, the R-7S-R and T-7S-R beams had $\phi 8 @ 100$ mm and $\phi 6 @ 112.5$ mm steel shear reinforcement in their monitored shear span, respectively. R-7S-R beam failed in bending with the yielding of the flexural reinforcement, followed by the concrete crushing (Figure 6b). In T-7S-R beam, the first shear crack became visible at the center of the $L_{i}$ span at a load of $160 \mathrm{kN}$, Figure 7b. Another shear crack formed at a load of $230 \mathrm{kN}$, almost parallel to the first shear crack, at about $500 \mathrm{~mm}$ from the support section.

As mentioned before, in the R-3L beam, the HCPs were bonded to the concrete beam by using epoxy adhesive. The failure of this beam occurred by the detachment of the HCPs at the load of $166 \mathrm{kN}$ (Figure 6c). At failure, a concrete cover layer varied between 5 to $10 \mathrm{~mm}$ was attached to the HCPs (Figure 6d).

After has been tested, the R-C-R beam was strengthened with two HCPs according to the arrangement indicated in Figure 4b. In spite of the intense state of damage of the R-C-R beam after has been tested, the stiffness of the R-D3L-B beam was even higher than the R-3L beam up to a load level of $150 \mathrm{kN}$, which means that the strengthening intervention adopted in the R-D-3L-B beam was capable of exceeding the stiffness of the R-3L beam. This demonstrates the high effectiveness of this technique when stiffness enhancement is required in a strengthening intervention. By increasing the load, the major shear crack of the damaged beam started widening and activated earlier the shear resisting contribution of the NSM-CFRP laminates of the HCPs.

In the T-5L-B beam the HCPs were bonded to the lateral faces of the beam using epoxy adhesive and fixed by 12 mechanical anchors (Figure 4c). The failure of this beam was localized at the web-flange zone of the beam (marked with a red ellipse in Figure 7c). In spite of the quite high increase of the shear capacity provided by the proposed technique (higher than possible to be ensured by other existing shear strengthening techniques), the shear strengthening effectiveness of the HCPs was not, however, fully exploited due to the strengthening discontinuity in 
this web-flange transition zone, and the inexistence of internal stirrups to offer resistance to the propagation of this type of crack.

The T-5L-BC beam was identical to T-5L-B beam, except that to offer resistance to the crack propagation through the web-flange zone, which occurred in the T-5L-B beam, steel bars working like in-plane shear connectors were applied to the beam as shown in Figure 4d. The first crack was detected between laminates number 2 and 3 at a load of 146 $\mathrm{kN}$ (Figure 7d). The HCP presents a more diffuse crack pattern than in the previous beam, with a preponderancy for flexural cracks, whose energy in its formation and the resistance of the SHCC to the propagation of a shear failure crack have contributed for the significant increase in terms of load carrying capacity and deflection performance registered in this beam.

Like it was done in the T-5L-BC beam, to avoid premature failure at the web-flange zone, four $\phi 10$ steel bars were applied to the T-D-5L-BC beam as shown in Figure 4e. Two micro cracks were detected by spraying oil (WD-40) on the surface of the HCP at a load of about $141 \mathrm{kN}$, in the zone of the existing shear crack on the T-C-R damaged beam. By increasing the load, these cracks propagated and widened followed by the formation of more micro cracks in this zone that did not degenerate in macro-cracks due to the reinforcement contribution of the CFRP laminates.

\section{Strains in the CFRP laminates}

The relationship between applied load and strain in the SG where the maximum CFRP strain was registered in the strengthened beams is shown in Figure 8. As mentioned in failure mode section, the R-3L beam failed due to detachment of the HCPs, then the CFRP laminates were not mobilized effectively. In consequence, the highest longitudinal strain in the CFRP laminates of the R-3L beam was recorded in the SG3 (Figure 4a) and was approximately $0.35 \%$, which corresponds to $21 \%$ of the ultimate strain of the CFRP laminates. Higher tensile strains in CFRP laminates were recorded in the beams strengthened with HCPs fixed with both adhesive and mechanical anchors. In fact, a maximum tensile strain of $1.8 \%$ was recorded in T-5L45-BC beam (Figure 8b), which is equal to the ultimate tensile strain of the CFRP laminates, indicating that this laminate was almost in its tensile rupture stage. This strain and all strain values herein reported are not necessarily the maximum ones, since a registered strain is dependent of the relative position of the SG with respect to the shear crack.

As mentioned before, the CFRP laminates in the repaired beams were designed to cross the existing crack, then the recorded strain for the repaired beams (R-D-3L-B and T-D-5L-BC) were different than those measured in the beams 
without damage, since the CFRP laminates were sooner mobilized in the damaged beams and the SGs were placed quite close to this crack.

In the R-D-3L-B beams, close to the peak load, the strain of the CFRP laminate started decreasing with the increase of load, which was caused by the migration of the major damage zone in the HCP towards the right extremity of the HCP where laminates were not applied, with the formation of the dominant failure crack (Figure 6e).

\section{Iosipescu shear test:}

Due to the relevance of knowing with good accuracy the fracture mode II parameters of the SHCC (namely the crack shear strength and the fracture energy) for modelling appropriately the shear contribution of this material, Iosipescu shear tests were executed with SHCC specimens. The dimensions of the specimens were $380 \times 140 \times 14.5 \mathrm{~mm}$ with depth of the critical cross section ( $h_{0}$ ) of $25 \mathrm{~mm}$, angle of notch root of $(\alpha) 90^{\circ}$, and tip radius at notches equal to ( r) $2.5 \mathrm{~mm}$ (Figure 2).

The test was conducted in a displacement controlled mode at a rate equal to $0.005 \mathrm{~mm} / \mathrm{s}$. The load was recorded using a $10 \mathrm{kN}$ load cell. The weight and the slight friction of the movable portion of fixture were taken into account on the evaluation of the strict load applied to the specimen. As shown in Figure 9, one LVDT was installed at the notched section to measure the sliding of the shear crack.

Ten specimens were tested. The average shear stress was determined by dividing the total applied load (P) (measured by the load cell) by the area of the cross section between the two notches $(A)$ :

$$
\tau_{\text {avg }}=\frac{P}{A}
$$

The envelope and the average curve corresponding to the average shear stress versus sliding relationship of the specimens are presented in Figure 10a. Figure 10b shows the typical crack pattern of the specimens.

\section{Numerical Simulations:}

\section{Iosipescu shear test}

The two dimensional multi-directional fixed smeared crack model described in [33], implemented in the FEM-based computer program FEMIX, is used in the numerical simulations of Iosipescu shear tests. To simulate the crack initiation and the fracture mode I propagation of SHCC, the tri-linear diagram represented in Figure 11a was adopted, 
which is defined by the parameters $\alpha_{i}$ and $\xi_{i}$, relating stress with strain at the transitions between the linear segments that compose this diagram. The ultimate crack strain, $\varepsilon_{n, u}^{c r}$, is defined as a function of the parameters $\alpha_{i}$ and $\xi_{i}$, the fracture energy, $G_{f}^{I}$, the tensile strength, $\sigma_{n, 1}^{c r}=f_{c t}$, and the crack bandwidth, $l_{b}$ [33]. The values of the parameters that define this diagram are indicated in Table 5. This table also includes the data necessary to define the shearsoftening diagram that simulates the crack shear stress transfer after crack initiation [34, 35], represented in Figure $11 \mathrm{~b}$, which is defined by the initial shear fracture modulus, $D_{t, 1}^{c r}$, and the peak crack shear strain, $\gamma_{t, p}^{c r}$, obtained using the crack shear strength (from the input data), $\tau_{t, p}^{c r}$, and the $D_{t, 1}^{c r}$. The ultimate crack shear strain, $\gamma_{t, \mathrm{u}}^{c r}$, depends on the $\tau_{t, p}^{c r}$, the mode II fracture energy, $G_{f, s}$, and the crack bandwidth, $l_{b}$. The first branch of the $\tau_{t}^{c r}-\gamma_{t}^{c r}$ diagram simulates the shear reinforcement mechanisms provided by aggregate interlock effect. Above a sliding level corresponding to $\gamma_{t, p}^{c r}$ the crack shear stress transfer decreases with the increases of the crack shear sliding, representing a crack shear softening stage, whose shear stress capacity is completely vanished when $\gamma_{t}^{c r} \geq \gamma_{t, u}^{c r}$, or when the crack becomes completely open $\left(\varepsilon_{n}^{c r} \geq \varepsilon_{n, u}^{c r}\right)$. Details about the physical meaning of the remaining variables of this constitutive model can be found elsewhere [33-35].

The SHCC used for the Iosipescu beam specimens can be considered to be an isotropic material due to the random orientation and high number of short fibers. Figure 12 represents the finite element mesh used for the simulation of the specimen. The FE mesh was composed by 1920 serendipity 4 nodes plain stress elements with $2 \times 2$ GaussLegendre integration scheme. The adopted mesh refinement was adopted after some preliminary simulations in terms of assuring mesh objectivity of the results. This figure also shows the support and load conditions.

For determining the fracture mode II parameters, an inverse analysis procedure was carried out by fitting as much as possible the experimental results by changing exclusively these parameters (Figure 13). The obtained results are indicated in Table 5. More information about the influence of shear retention factor, fracture energy of mode II, and crack shear strength on the average shear stress-sliding response of the SHCC can be found in [27].

\section{Numerical simulation of the tested beams}

The three dimensional multi-directional fixed smeared crack model described in detail in Ventura-Gouveia [35] was used in the numerical simulations of the beams. The values of the parameters defining the diagrams of Figure 11 for 
plain concrete are provided in Table 6. The data for the shear softening diagram of plain concrete was determined by calibrating the model to match as closely as possible the force-deflection relationship recorded in the tests of the control beams. Figures 14 and 15 represent the finite element mesh adopted for the RC beam representative of series A and B, respectively.

To introduce the main shear crack in the model for simulating the level of damages already existing in the R-D-3L-B and T-D-5L-BC beams before strengthening, a much lower tensile strength and mode I fracture energy were attributed $\left(0.1 \mathrm{~N} / \mathrm{mm}^{2}\right.$ and $0.0007 \mathrm{~N} / \mathrm{mm}$, respectively) to the elements crossing this shear crack (hatched elements in Figures 14 and 15), in order these elements behaved in a very brittle nature, forcing the occurrence of the observed shear crack almost from the beginning of the loading process of these beams. For the other parameters of the constitutive model, values equal to the remaining concrete elements were adopted.

Taking advantage of the symmetry of the beams only half length of the beam was considered in the simulations in order to reduce the computational time. Serendipity 8 nodes solid elements with $2 \times 2 \times 2$ Gauss-Legendre integration scheme were used for both the concrete and SHCC (three degrees-of-freedom per node). The steel stirrups, longitudinal steel bars and CFRP laminates were modeled with 3D embedded cables of 2 nodes (one degree-offreedom per node), by using a 2 Gauss-Legendre integration scheme, and perfect bond to the surrounding medium was assumed. The bolts were modeled with 3D two-node truss elements, and the confinement effect locally induced on concrete by the torque applied to the anchors was simulated by applying a temperature decrease of $-25.5^{\circ} \mathrm{C}$ in these elements, evaluated according to the following equations:

$$
\begin{array}{ll}
F=\frac{\tau}{r} & F=\frac{20}{0.005}=4000 \mathrm{~N} \\
\sigma=\frac{F}{A} & \sigma=\frac{4000}{78.5}=51 \mathrm{MPa} \\
\varepsilon=\frac{\sigma}{E}=T . \alpha & \varepsilon=\frac{51}{200000}=T \times 10^{-5}
\end{array}
$$

where $\tau$ is the torque (N.m), and $r, A$ and $E$ are the radius, cross sectional area, and elasticity modulus of the bolt (5 $\mathrm{mm}, 78.5 \mathrm{~mm}^{2}$, and $200 \mathrm{GPa}$ ), respectively. In these equations $T$ and $\alpha$ are the temperature variation and the coefficient of thermal expansion, respectively. Figure 16 illustrates the application of the torque and the development of the axial force in the fastener.

An elasto-perfectly plastic model was adopted to simulate the tension and compression behavior of the steel reinforcements, whose fundamental information is indicated in Table 3. For modeling the NSM CFRP laminates, a 
linear elastic stress-strain relationship was adopted up to their ultimate tensile capacity. The tested beams showed that no slip occurred between the concrete substrate and the SHCC plates, thus the assumption of perfect bond between substrate and SHCC plates was assumed.

The experimental and numerical relationships between the applied load and the deflection at the loaded section for the tested beams are compared in Figures 17 and 19. The numerical simulations ended at the last converged load increment. The crack patterns of these beams at the end of the analysis are represented in Figures 18 and 20 . These figures show that the numerical model is capable of predicting with high accuracy the relationship between the load and the deflection of the strengthened and repaired beams, and capturing with a good precision the localization and profile of the failure cracks. For the beams strengthened with $\mathrm{HCP}$, the crack pattern is represented for the lateral surface of the concrete substrate, as well as for the HCP. The crack pattern of the T-5L-B beam shows the tendency of the failure crack to propagate at the web-flange interface due to the different width of the web and flange of the beam's cross section, as well as the interruption of the shear strengthening provided by the HCPs just below the bottom surface of the flange. This also justifies the high strengthening contribution of the steel bars applied in the T-5L-BC and T-D-5L-BC beams, since these bars, by crossing this zone, have offered resistance to the propagation of this crack.

\section{Assessing the Potentialities of the Developed Strengthening Technique}

The computer program, whose good predictive performance for the simulation of the behavior of the structures under consideration was confirmed in the previous section, was adopted to further explore the potentialities of this strengthening technique. For this purpose, it was investigated the influence on the load carrying capacity and failure mode when using mortar instead of SHCC, changing the level of concrete confinement by different torque value applied to the mechanical anchors, and the application of an adhesive material that assures perfect bond between HCPs and concrete substrate.

The arrangement of the steel reinforcement, the material properties of concrete, SHCC, and CFRP laminates, and the support and load conditions were the same of the ones adopted in the numerical simulations of the $\mathrm{T}$ cross section beams of the previous section. In these simulations the beams have the same configuration of the T-5L-BC. The level of concrete confinement was changed by modifying the torque applied to the mechanical anchors. Three different torque levels were chosen: 10 N.m, 20 N.m, and 40 N.m. 


\section{Influence of using mortar instead of SHCC in the HCPs}

The relationship between the load and the deflection at loaded section obtained for the beam strengthened with HCPs (T-5L-BC) and mortar plates (T-MP-5L-BC) is compared in Figure 21. It is assumed the mortar plate has the same dimensions $\left(800 \times 300 \times 20 \mathrm{~mm}^{3}\right)$ and CFRP reinforcement of the HCPs, and also it has the same material properties of the concrete substrate. As expected, the beam consisting of mortar failed at a lower $(474 \mathrm{kN})$ load and deflection $(7.3$ $\mathrm{mm}$ ) than of the beam strengthened with HCPs. The crack patterns of these beams at maximum load of the T-MP-5LBC beam are compared in Figure 22. The crack pattern of the mortar plate shows more fully open cracks than HCPs due to the much lower mode I fracture energy, which has anticipated the loss of shear strengthening contribution of the mortar panels reinforced with CFRP laminates.

\section{Influence of the torque level applied to the mechanical anchors:}

As mentioned before, the mechanical anchors can prevent the premature detachment of the HCPs, and provide some confinement to the concrete core. The torque was simulated by applying a temperature decrease of $-12.75^{\circ} \mathrm{C},-23^{\circ} \mathrm{C}$, and $-51^{\circ} \mathrm{C}(10$ N.m, 20 N.m, and 40 N.m, respectively) in these elements, by following Eq. (2). In Figure 23 the loaddeflection curves obtained for these three torque levels applied to the mechanical anchors are compared. As expected, the load carrying capacity of the beam and its ultimate deflection have increased with the torque level. The crack patterns of these beams at the failure stage of the beam with the minimum torque (T-5L-T10) are presented and compared in Figure 24, being visible that by increasing the torque level the numbers of fully open cracks have decreased, with a consequent benefit in terms of shear capacity.

\section{Influence of adhesive on the load carrying capacity:}

Since the experimental tests evidenced that no slip has occurred between HCPs and concrete substrate when an epoxybased adhesive was used, a perfect bond between these two materials was assumed in the previous numerical simulations. To assess how these perfect bond conditions are relevant on the beam's load carrying capacity, other simulations were executed by introducing a thin layer $(1 \mathrm{~mm})$ of very soft material between HCPs and concrete substrate for simulating an almost free sliding capacity between these materials when an adhesive bond layer is not used. This soft material was assumed linear-elastic with a very low young's modulus (1 MPa) in order to simulate the relevant damage phenomena in the HCPs when an almost free sliding and separation between these two materials are 
allowed. Specific experimental research must be executed for characterizing the fundamental parameters of the constitutive law of 3D interface finite elements, like the frictional angle value and its dependence on the sliding and opening process between HCPs and beam's concrete substrate, which is out-of-scope of this work in the present phase. To assess the influence of pressure between these two materials in the stress transfer between them, different torque levels were simulated (20 N.m and 40 N.m). Since the contribution of the shear resisting mechanisms of the bolts must be simulated for capturing the local damage that might occur in the HCPs around the bolts when perfect bond between HCPs and concrete substrate is not assured, a new mesh was adopted (Figure 25). In this mesh, solid elements were used to simulate the mechanical anchors (black circle in Figure 25 show the position of the mechanical anchors). The T-5L-BC beam was the selected one for the present simulations.

Figure 26a shows that the load carrying capacity decrease when perfect bond between HCPs and concrete substrate is not assured. This is caused by the development of high strain gradients in the HCPs around the anchors, and, consequently, high damage in these zones (Figures 26b and 26c). A favorable effect on the beam's load carrying capacity occurs with the increase of the torque level applied to the mechanical anchors causing a better confinement of the materials of the zones, which delays the occurrence of damage due to cracking, and also increases the frictional resistance between HCPs and concrete substrate.

\section{Conclusions}

The effectiveness of Hybrid Composite Plates (HCPs) for the shear strengthening of damaged reinforced concrete (RC) beams was investigated by carrying out an experimental program. The control beams, without shear reinforcement, were loaded up to failure, and then repaired by using HCPs. The experimental program demonstrated the relevance of using not only epoxy adhesive but also mechanical anchors for fixing the HCPs to the concrete beam to be strengthened, in order to avoid the premature detachment of the HCPs when only adhesive is used. A numerical and parametric study were executed to evaluate the influence of relevant aspects of the proposed strengthening technique on the load carrying capacity of the beams, namely: 1) use a mortar instead of SHCC on the HCP; 2) application of different torque level to the mechanical anchors; 3) different bond conditions between HCPs and concrete substrate. From the obtained results, the following conclusions can be drawn:

- When HCPs were applied to the damaged beams the load carrying capacity was $97 \%$ and $96 \%$ of its corresponding virgin beam strengthened with the same HCPs. 
- The HCPs were effective on arresting the propagation of the existing shear failure crack, and more cracks formed in another zone of the beam during the loading process, assuring to the strengthened beams a behavior similar to the corresponding undamaged strengthened beams.

- The shear behavior of the SHCC was investigated by carrying out Iosipescu shear tests. For an average slip two times higher the average slip at peak load the SHCC was still capable of supporting $50 \%$ of the average shear strength, which denotes the ductility of this composite material when subjected to shear deformations.

- The capability of a FEM-based computer program to predict with high accuracy the behavior of this type of structures up to its collapse was demonstrated.

- The crack shear softening diagram available in the FEMIX computer program allowed to predict the load carrying capacity, crack pattern and failure mode of the tested beams.

- When mortar was used instead of SHCC, the beam failed at a lower load and deflection, since the strain hardening character of the SHCC assured a much more diffuse crack pattern in the HCP, with a consequent better mobilization of the high tensile capacity of the CFRP laminates.

- The load carrying capacity and deformability performance of this type of strengthened beams have increased with the torque level applied to the mechanical bolts due to the higher confinement applied to the concrete.

- The load carrying capacity of the beam without adhesive as a bond between HCPs and concrete substrate is about $65 \%$ of the beam where a bond material is adopted for assuring perfect (no sliding between HCPs and substrate) bond conditions between these two materials.

\section{ACKNOWLEDGMENTS}

The second author wish to acknowledge the grant SFRH/BSAB/114302/2016 provided by FCT. The authors also thank the collaboration of the following companies: Clever Reinforcement Iberica for providing the CFRP laminates and epoxy, Sika for the sand and adhesive, Grace for the superplasticizers, Dow Chemical Co. for viscous modifying agents, ENDESA Compostilla power station for the fly ash, and Casais for assisting in the execution of the beams. 


\section{References:}

1. Abdel-Jaber, M.S., Walker, P.R., Hutchinson, A.R., Shear strengthening of reinforced concrete beams using different configurations of externally bonded carbon fiber reinforced plates. Materials and Structures, 2003. 36: p. 291-301.

2. Valerio, P., Ibell, T.J., Darby, A.P., Deep embedment of FRP for concrete shear strengthening. Proceedings of the Institution of Civil Engineers-Structures and Buildings, 2009. 162(5): p. 311-321.

3. Khalifa, A., Gold, W.J., Nanni, A., Aziz, A., Contribution of externally bonded FRP to shear capacity of RC flexural members. Composites for Construction 1998. 2(4): p. 195-203.

4. Saafan, M.A.A., Shear Strengthening of Reinforced Concrete Beams Using GFRP Wraps. Acta Polytechnica, 2006. 46: p. 24-32.

5. Rezazadeh, M., Costa, I., Barros, J., Influence of prestress level on NSM CFRP laminates for the flexural strengthening of RC beams. Composite Structeres, 2014. 116: p. 489-500.

6. Khalifa, A., Nanni, A., Improving shear capacity of existing RC T-section beams using CFRP composites. Cement \& concrete Composites, 2000. 22: p. 165-174.

7. De Lorenzis, L., Nanni, A., Shear Strengthening of Reinforced Concrete Beams with Near-Surface Mounted Fiber-Reinforced Polymer Rods. ACI Structural Journal, 2001. 98: p. 60-68.

8. Chaallal, O., Mofidi, A., Benmokrane, B., Neale, K., Embedded Through-Section FRP Rod Method for Shear Strengthening of RC Beams: Performance and Comparison with Existing Techniques. Composites for Construction, 2011. 19: p. 374-383.

9. Capozucca, R., Domizi, J., Magagnini, E. , Damaged RC beams strengthened with NSM CFRP rectangular rods under vibration in different constrain conditions. Composite Structures, 2016. doi:10.1016/j.compstruct.2016.07.044.

10. Al-Sulaimani, G.J., Sharif, A., Basunbul, I. A., Baluch, M. H., and Ghaleb, B.N., Shear repair for reinforced concrete by fiberglass plate bonding. ACI Structural Journal, 1994. 91(4): p. 458-464.

11. Alzoubi, F., Qi, Z., Zheng-ling, L., Shear strengthening of pre-damaged reinforced concrete beams with carbon fiber reinforced polymer sheet strips. Journal of Chongqing University: English Edition, 2007. 6: p. 305-310. 
12. Jayaprakash, J., Abdul Samad, A. A., Anvar Abbasovich, A. and Abang Ali, A. A., Shear capacity of precracked and non-precracked reinforced concrete shear beams with externallybonded bi-directional CFRP strips. Construction and Building Materials, 2008. 22(6): p. 1148-1165.

13. Dirar, S., Lees, J.M., and Morley, T.C., Precracked Reinforced Concrete T-Beams Repaired in Shear with Prestressed Carbon Fiber-Reinforced Polymer Straps. ACI Structural Journal, 2013. 110(5): p. 855-866.

14. Khalifa, A., Tumialan, G., Nanni, A., Belarbi, A., Shear Strengthening of Continuous RC Beams Using Externally Bonded CFRP Sheets, in 4th International Symposium on FRP for Reinforcement of Concrete Structures (FRPRCS4)1999: Baltimore. p. 995-1008.

15. Mofidi, A., Chaallal, O., Shear Strengthening of RC Beams with EB FRP: Influencing Factors and Conceptual Debonding Model. Journal of Composites for Construction, 2011. 15: p. 62-74.

16. Baghi, H., The effectivness of SHCC-FRP panles of the shear resistance of RC beams, 2015, University of Minho.

17. Shang, Q., Zijl, G.V., Characterising the Shear Behaviour of Strain-Hardening Fiber-Reinforced CementBased Composites. Journal of the South African Institution of Civil Engineering, 2007. 49: p. 16-23.

18. Chalioris, C.E., Sfiri, E.F. Shear Performance of Steel Fibrous Concrete Beams in The Proceedings of the Twelfth East Asia-Pacific Conference on Structural Engineering and Construction — EASEC12. 2011.

19. Mechtcherine, V., Millon, O., Butler, M., Thoma, K., Mechanical Behavior of SHCC under Impact Loading, in High Performance Fiber Reinforced Cement Composites 6, G.J. Parra-Montesions, Reinhardt, H.W., Naaman, A.E., Editor 2012, RILEM. p. 297-304.

20. Dias, S.J.E., Barros, J.A.O., Performance of reinforced concrete T beams strengthened in shear with NSM CFRP laminates. Engineering Structures, 2010. 32: p. 373-384.

21. Yu, B., Kodur, V.K.R., Effect of high temperature on bond strength of near-surface mounted FRP reinforcement. Composite Structures, 2014. 110: p. 88-97.

22. Banks-Sills, L., Arcan, M., An Edge Crack Mode II Fracture Specimen. Experimental Mechanics, 1983: p. 257-261.

23. Ohno, K., Shear Tests of Reinforced Concrete Beam by Special Type of Loading. Transactions of the Architectural institute of Japan 1957: p. 581-584. 
24. Reinhardt, H.W., Ozbolt, J., Xu, S., Dinku, A., Shear of Structural Concrete Members and Pure Mode II Testing. Advanced Cement Based Materials 1997. 5: p. 75-85.

25. Boulifa, R., M. Laid-Samami, and M. Tayeb benhassine, A New Technique for Studying the Behaviour of Concrete in Shear. Journal of King Saud University, 2013. 25(2): p. 149-159.

26. Iosipescu, N., New accurate method for single shear testing of metals. Journal of Materials, 1967. 3: p. 537566.

27. Baghi, H., Barros, A.O.J., Shear Properties of the Strain Hardening Cementitious Composite Material. Journal of Materials in Civil Engineering (ASCE), 2016. DOI: 10.1061/(ASCE)MT.1943-5533.0001603.

28. de Normalisation, C.E., Concrete - Part 1: Specification, performance, production and conformity, 2000, EN206-1, CEN. . p. 69.

29. ISO, E., Metallic materials Tensile testing-Part 1: Method of test (at ambient temperature), 1990, Brussels: European committee for standardization (cen).

30. Moridis, G.J., M. T. Reagan, S.-J. Kim, Y. Seol, and K. Zhang, Evaluation of the gas production potential of marine hydrate deposits in the Ulleung Basin of the Korea East Sea. SPE Journal, 2009. 14(4).

31. Myshakin, E.M., B. J. Anderson, K. Rose, and R. Boswell, Simulations of Variable Bottomhole Pressure Regimes to Improve Production from the Double-Unit Mount Elbert, Milne Point Unit, North Slope Alaska Hydrate Deposit. Energy \& Fuels, 2011. 25(3): p. 1077-1091.

32. du Béton, C.E.I., CEB-FIP model code 2010, first completed draft, 2010, Comité Euro-International du Béton, Lausanne, Switzerland.

33. Sena-Cruz, J.M., Strengthening of concrete structures with near-surface mounted CFRP laminate strips, in Department of Civil Engineering, PhD Thesis, 2004, University of Minho.

34. Barros, J.A.O., Baghi, H., Dias, S.J.E., Ventura-Gouveia. A., A FEM-based model to predict the behaviour of RC beams shear strengthened according to the NSM technique. Engineering Structures, 2013. 56: p. 11921206.

35. Ventura-Gouveia, A., Constitutive models for the material nonlinear analysis of concrete structures including time-dependent effects, in Department of Civil Engineering, PhD Thesis,2011, University of Minho. 



\section{LIST OF FIGURE CAPTIONS}

Figure 1: Schematic representation of Hybrid Composite Plates (HCPs) for shear strengthening of reinforced concrete beams

Figure 2: Geometry of the notch in the Iosipescu shear test

Figure 3: Configuration and geometry of the beams (dimensions in $\mathrm{mm}$ )

Figure 4: Geometry of the strengthened beams (dimensions in $\mathrm{mm}$ )

Figure 5: Load-deflection at loaded section of series: a) rectangular cross section, b) T cross section beams Figure 6: Crack pattern at the failure of the beams of series A (rectangular cross section beams): a) R-C-R; b) R-7S-R; c and d) R-3L; e) R-D-3L-B

Figure 7: Crack pattern at the failure of the T-Cross section of the tested beams

Figure 8: Force vs. strain in the SG of the monitored laminates where the maximum strain was registered a) rectangular cross section beams; b) T-cross section beams

Figure 9: The position of the LVDT to measure the sliding of the shear crack formed in the notched section

Figure 10: a) The envelope and average shear stress versus crack sliding; b) Typical crack pattern in the tested Iosipescu specimens

Figure 11: a) Tri-linear crack normal stress vs. crack normal strain diagram to simulate the fracture mode I crack propagation b) Diagram to simulate the relationship between the crack shear stress and the crack shear strain component, and possible shear crack statuses

Figure 12: Finite element mesh of the Iosipescu specimen

Figure 13: Comparison between experimental and numerical average shear stress versus sliding relationship

Figure 14: Geometry, mesh and support conditions of the representative rectangular cross section beam of series A (dimensions in $\mathrm{mm}$ )

Figure 15: Geometry, mesh and support conditions of the representative $\mathrm{T}$ cross section beam of series B (dimensions in $\mathrm{mm}$ )

Figure 16: The relation between applied torque to axial tension force fastener

Figure 17: Comparison between experimental and numerical relationships of force vs. deflection at the loaded section of rectangular beams

Figure 18: Crack pattern of the beams of rectangular cross section (in gray color: crack completely open; in black color: crack in the opening process)

Figure 19: Comparison between experimental and numerical relationships of force vs. deflection at the loaded section of $\mathrm{T}$ cross section beams

Figure 20: Crack pattern of the beams of T cross section (in gray color: crack completely open; in black color: crack in the opening process)

Figure 21: Influence of mortar instead of SHCC on the relationship between the force and the deflection at loaded section

Figure 22: Influence of mortar instead of SHCC on the crack patterns at ultimate load of the strengthened beam with mortar plates (in gray color: crack completely open; in black color: crack in the opening process)

Figure 23: Influence of the torque level applied on the mechanical bolts on the relationship between the force and the deflection at loaded section

Figure 24: Influence of the torque level applied on the mechanical anchors on the crack patterns at the ultimate load of the beams with the lowest torque level (T-5L-T10) (in gray color: crack completely open; in black color: crack in the opening process) 
Figure 25: New mesh to simulate the effect of strain gradients on the HCPs around the anchors when perfect bond between HCPs and concrete substrate is not assured

Figure 26: Effect of strain gradients due to shear deformation of mechanical anchors on load carrying capacity and crack pattern 

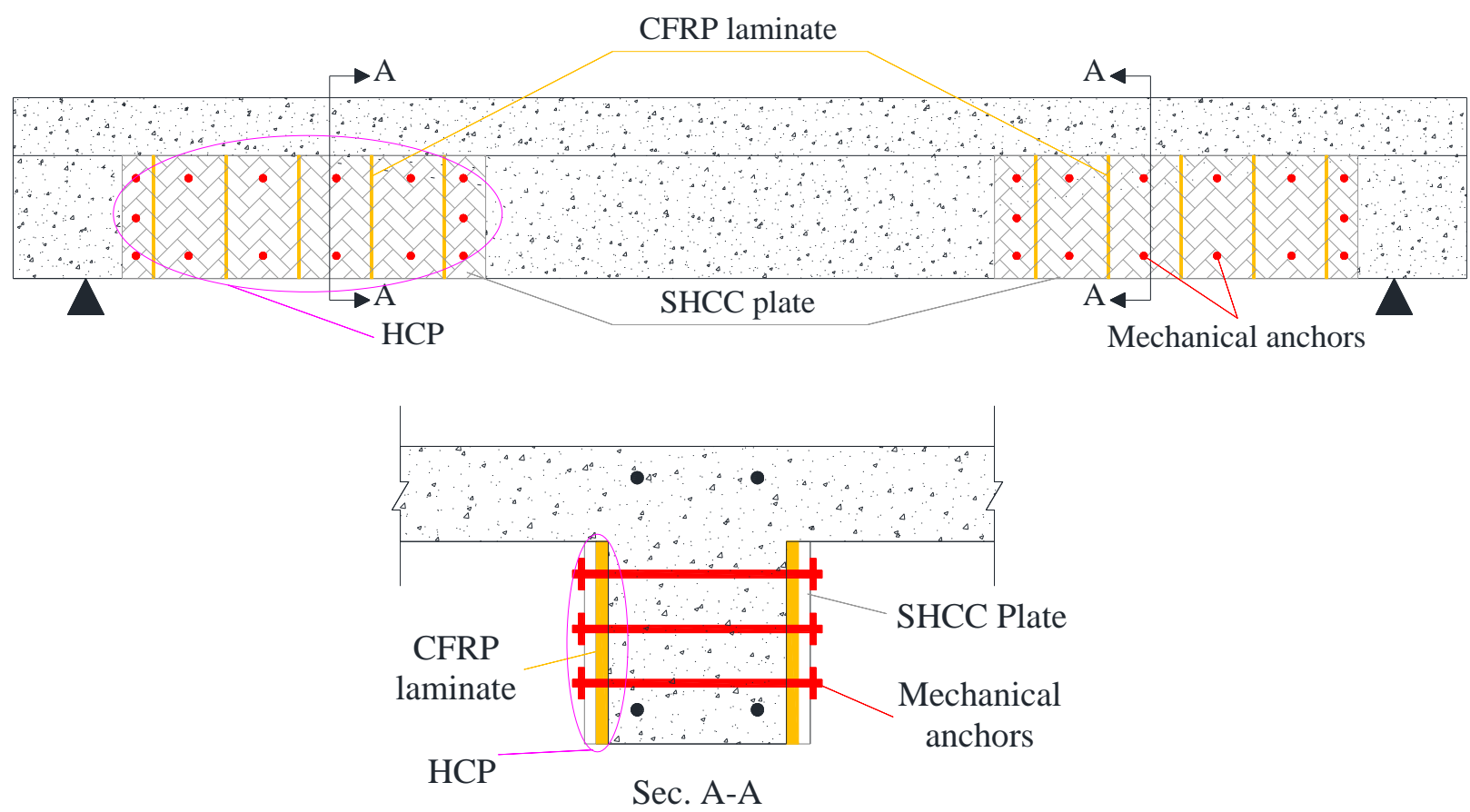

Figure 1: Schematic representation of Hybrid Composite Plates (HCPs) for shear strengthening of reinforced concrete beams 


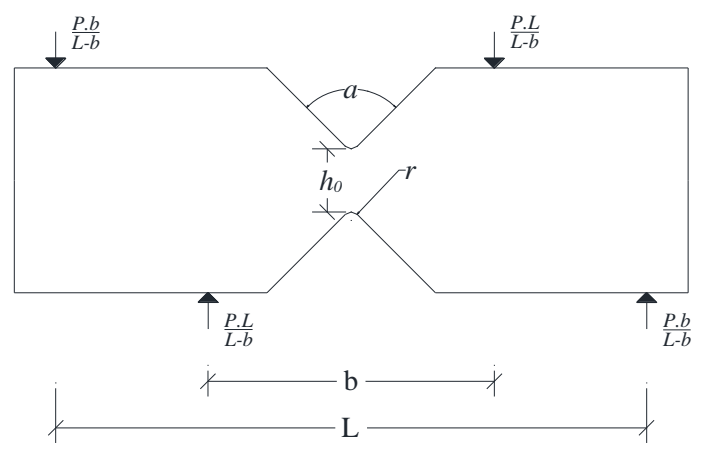

a) Load configuration

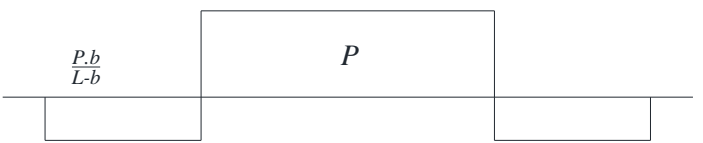

b) Shear diagram

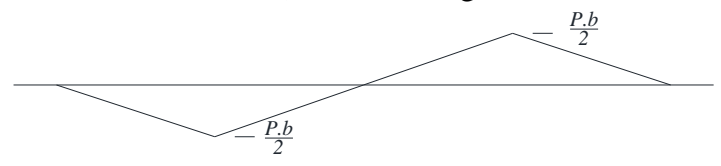

c) Moment diagram

Figure 2: Geometry of the notch in the Iosipescu shear test 

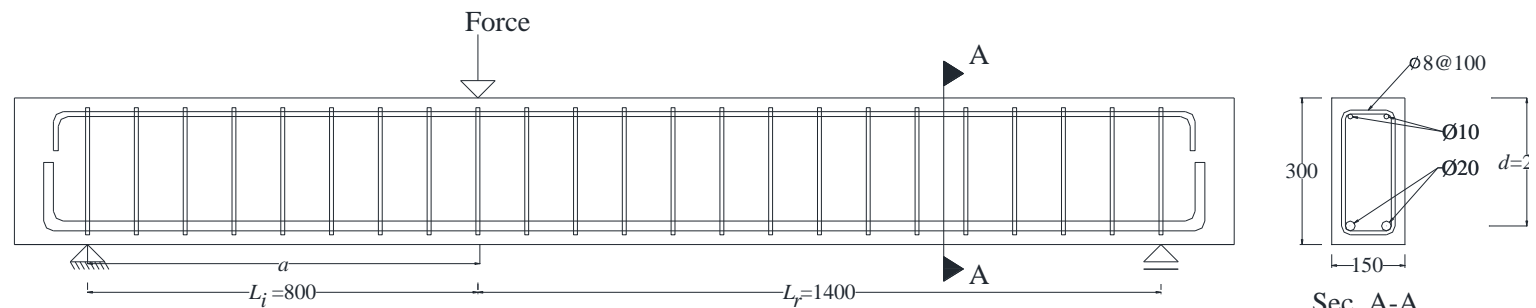

Sec. A-A

$\varangle$
$\stackrel{\infty}{=}$
$\stackrel{0}{\omega}$

Type 1

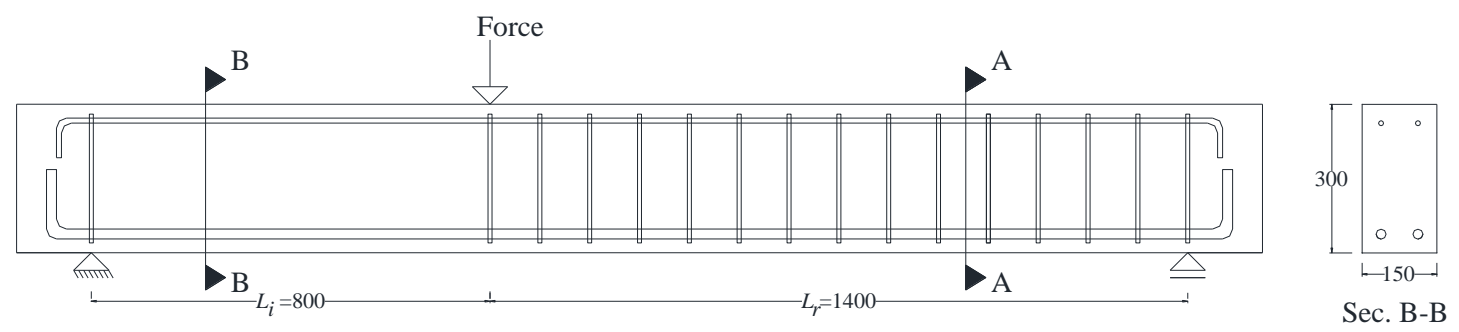

Type 2

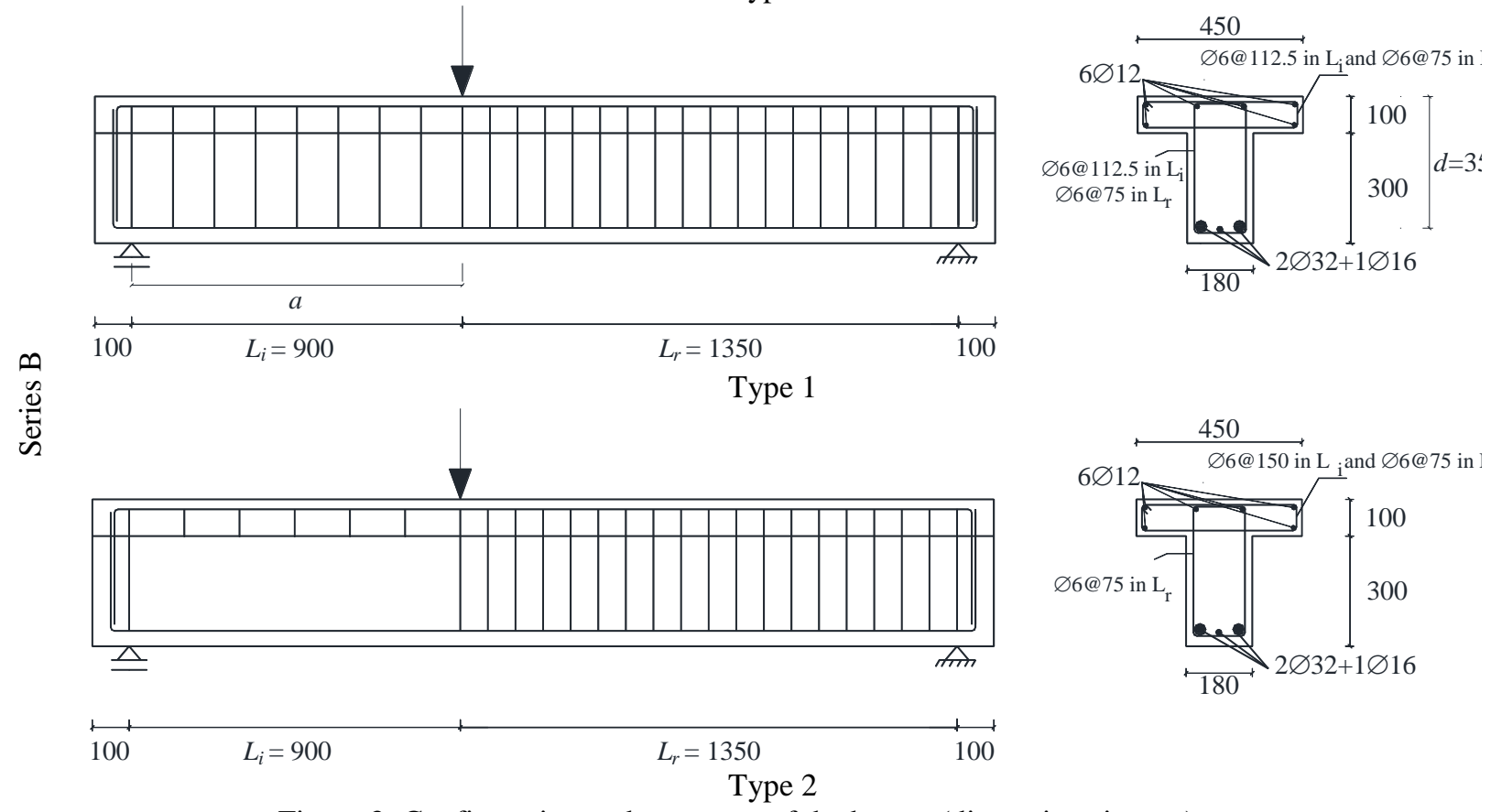

Figure 3: Configuration and geometry of the beams (dimensions in $\mathrm{mm}$ ) 

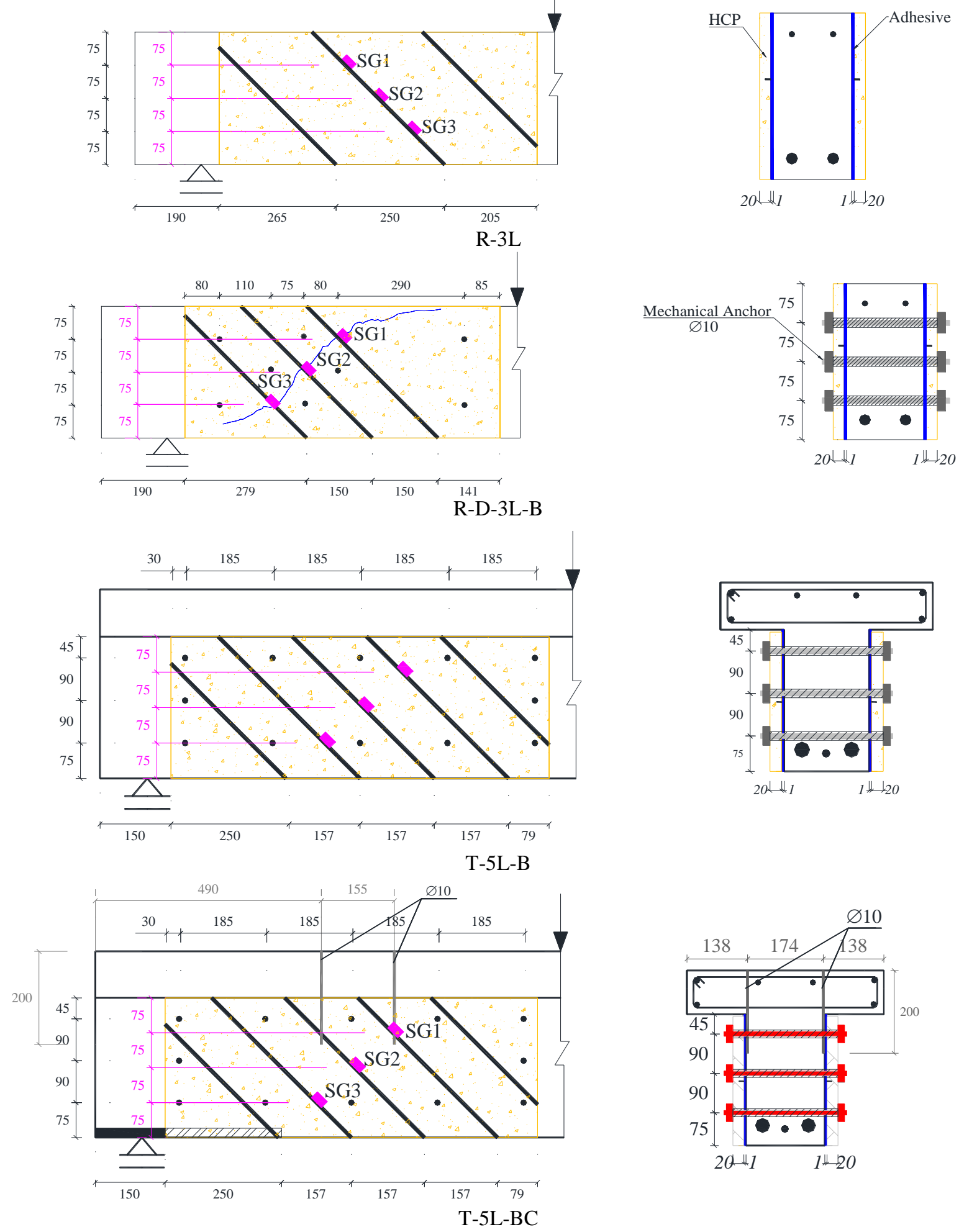

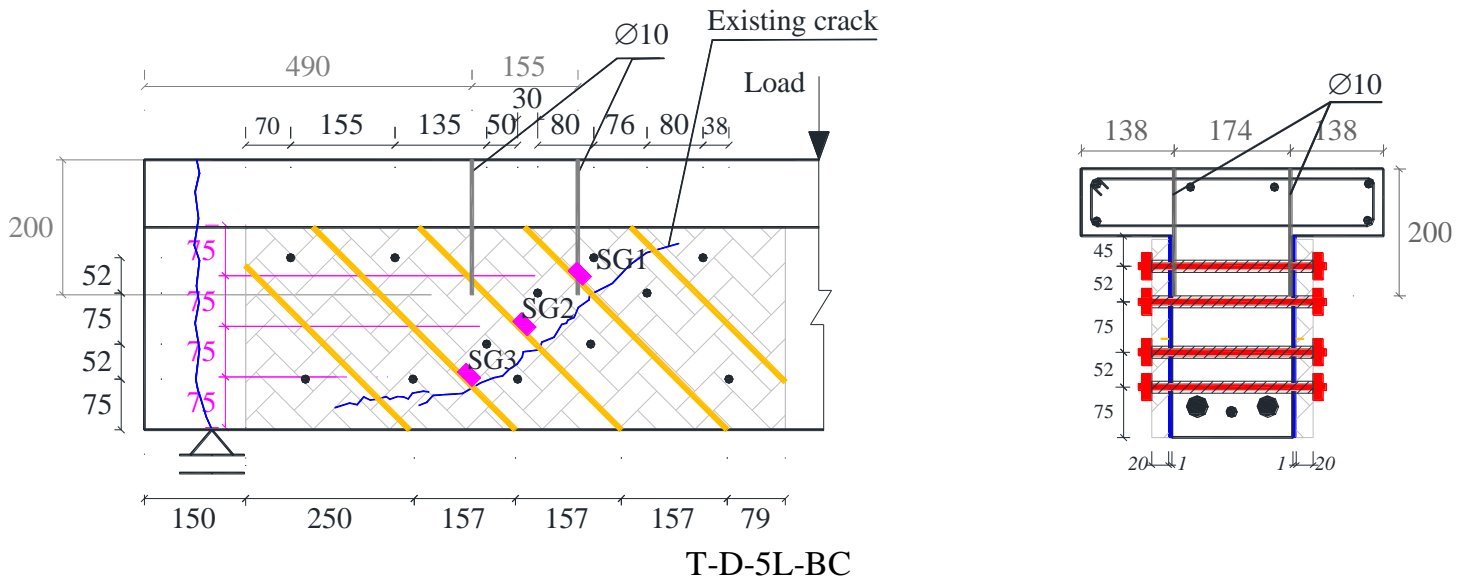

Figure 4: Geometry of the strengthened beams (dimensions in $\mathrm{mm}$ ) 


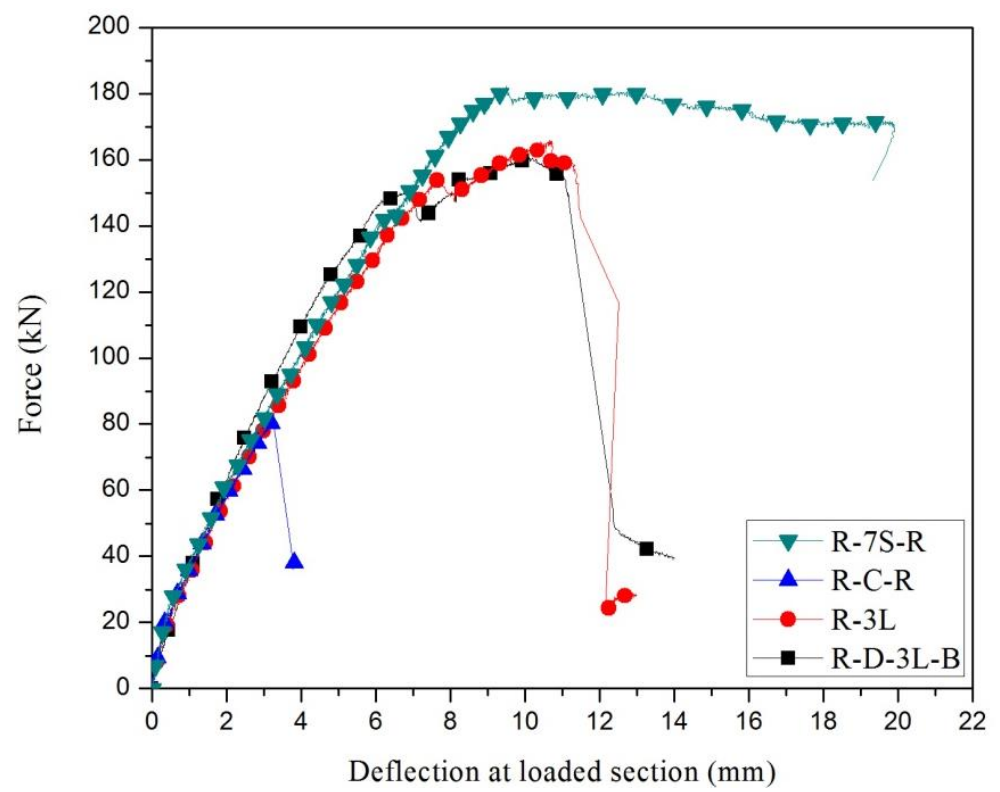

a)

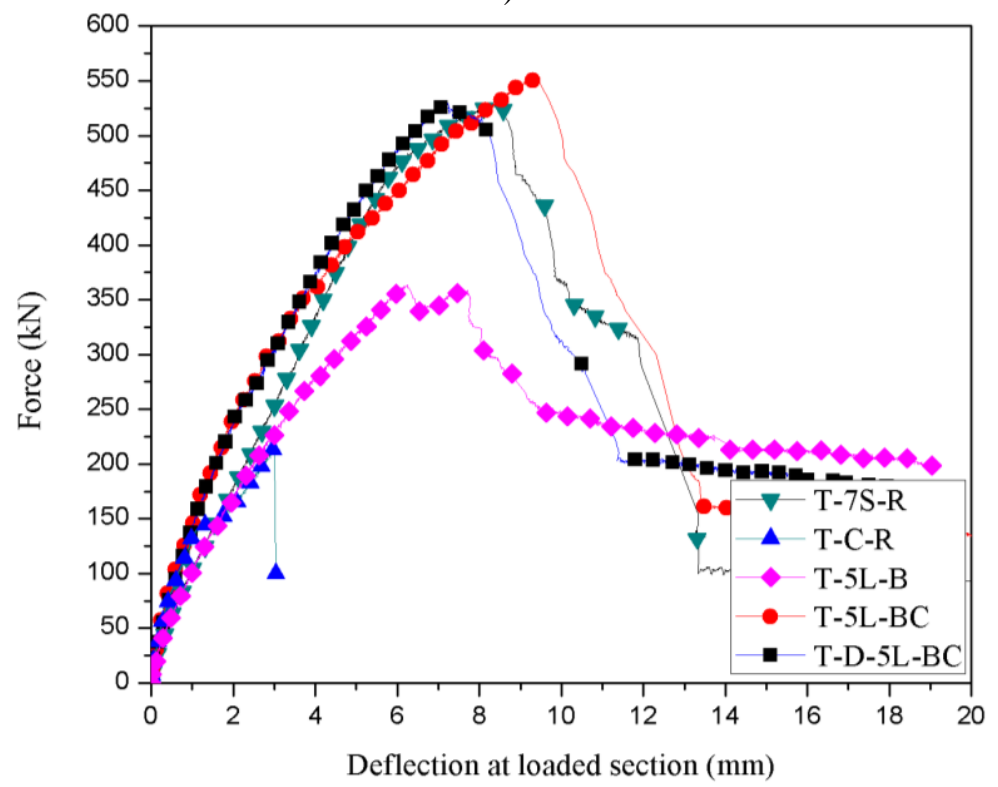

b)

Figure 5: Load-deflection at loaded section of series: a) rectangular cross section, b) $\mathrm{T}$ cross section beams 


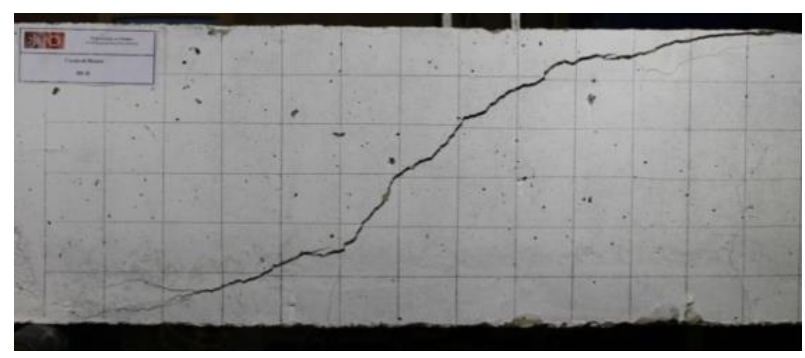

a) Crack pattern at failure load of the R-C-R beam

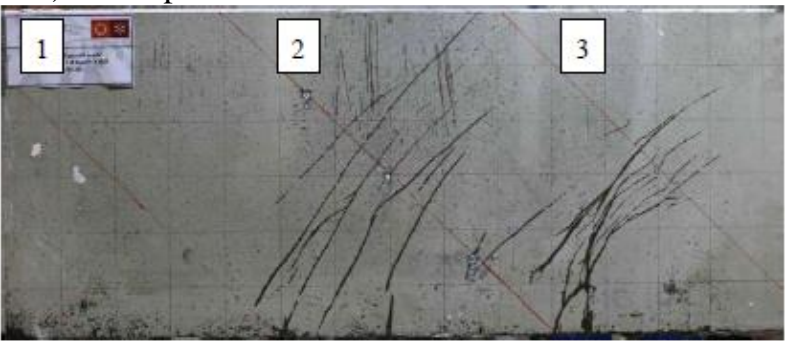

c) Crack pattern in the lateral surface of R-3L beam at failure load

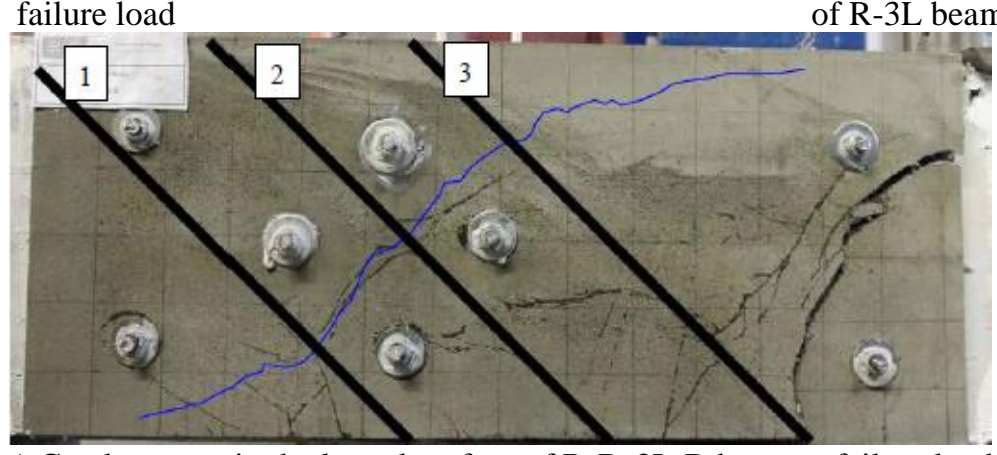

e) Crack pattern in the lateral surface of R-D-3L-B beam at failure load

Figure 6: Crack pattern at the failure of the beams of series A (rectangular cross section beams): a) R-C-R; b) R-7S$\mathrm{R}$; c and d) R-3L; e) R-D-3L-B

\section{b) Crack pattern at failure load of the R-7S-R beam}

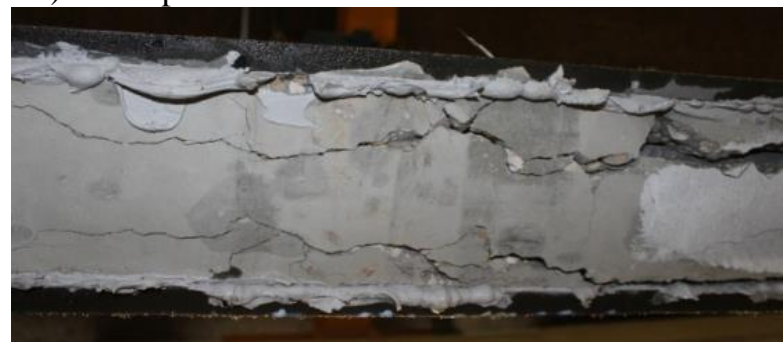

d) Crack pattern in the bottom surface at failure load of R-3L beam

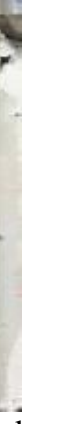




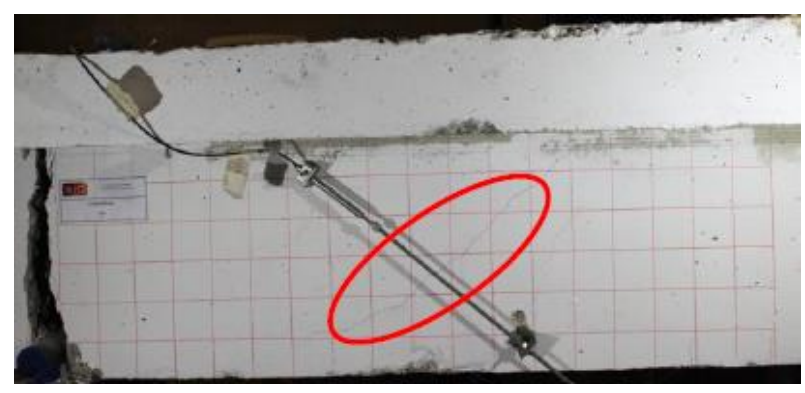

a) Crack pattern at failure load of T-C-R beam

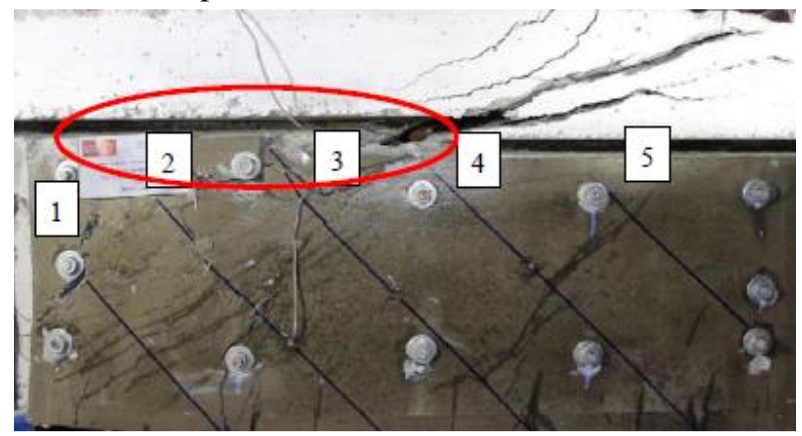

c) Crack pattern in the lateral surface of T-5L-B beam at failure load

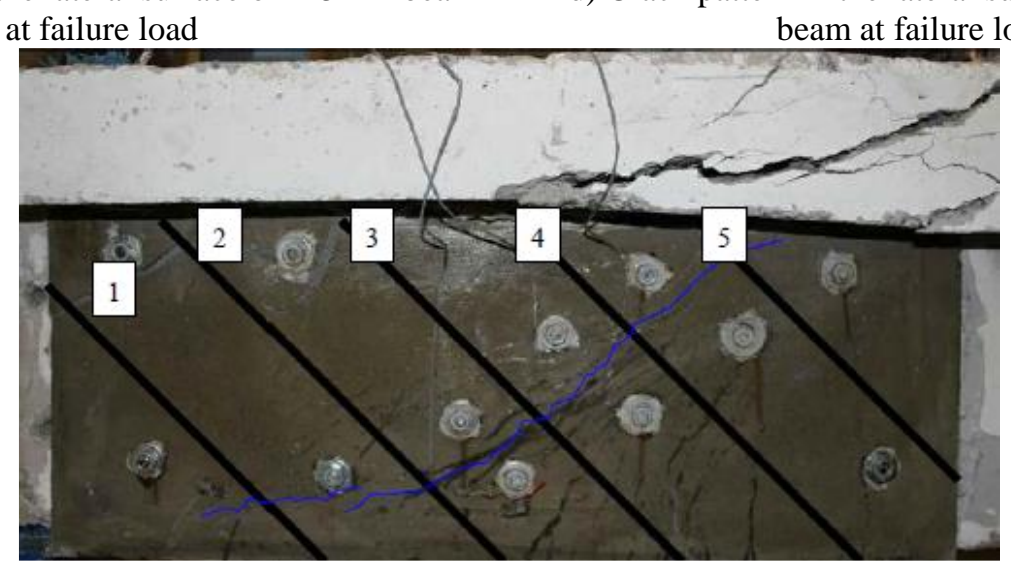

e) Crack pattern in the lateral surface of T-D-5L-BC beam at failure load

Figure 7: Crack pattern at the failure of the beams of series B (T cross section beams): a) T-C-R; b) T-7S-R; c) T5L-B; d) T-5L-BC; e) T-D-5L-BC 


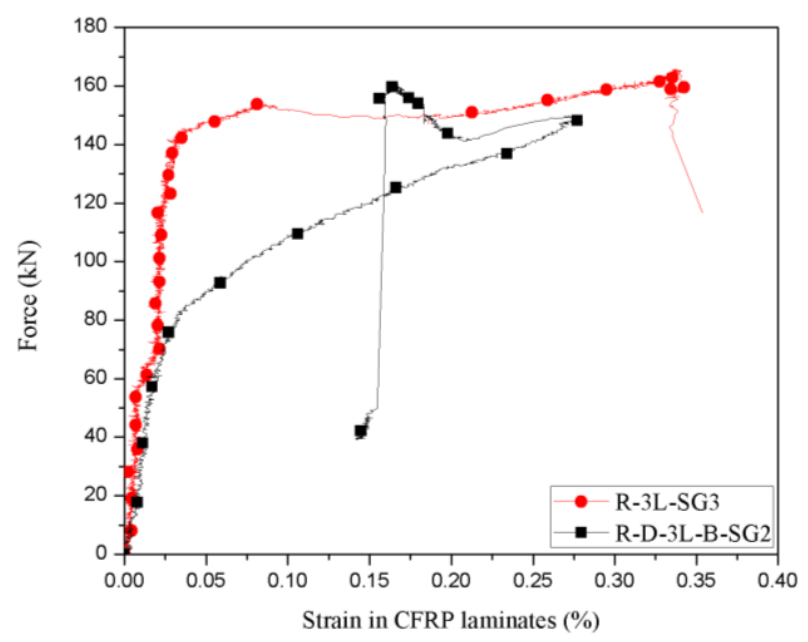

a)

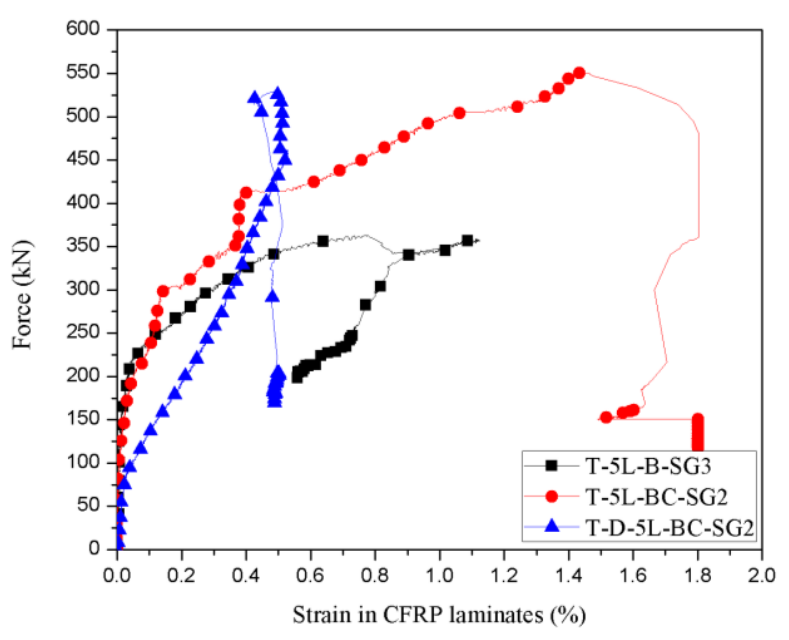

b)

Figure 8: Force vs. strain in the SG of the monitored laminates where the maximum strain was registered a)

rectangular cross section beams; b) T-cross section beams 


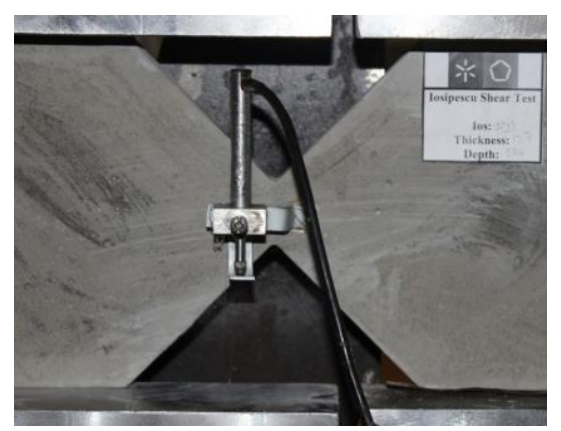

Figure 9: The position of the LVDT to measure the sliding of the shear crack formed in the notched section 


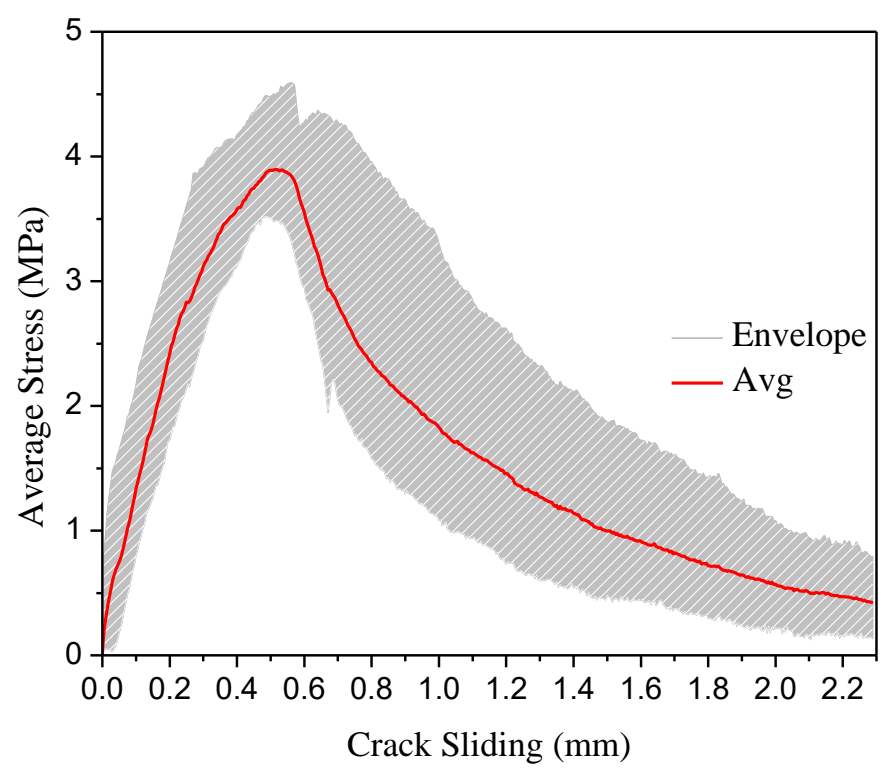

a)

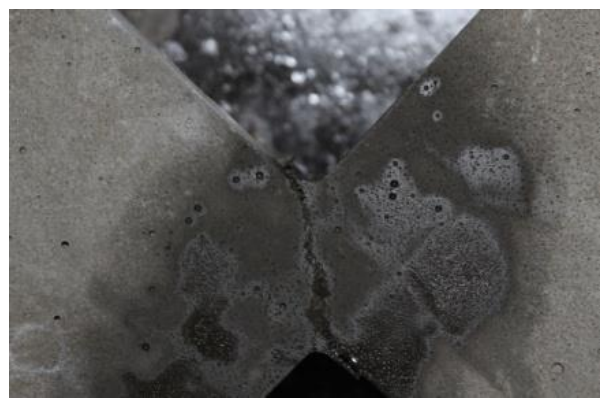

b)

Figure 10: a) The envelope and average shear stress versus crack sliding; b) Typical crack pattern in the tested Iosipescu specimens 


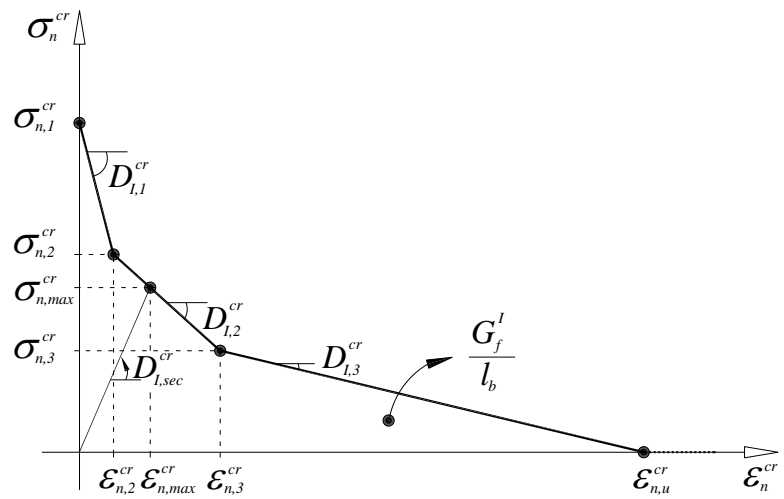

a)

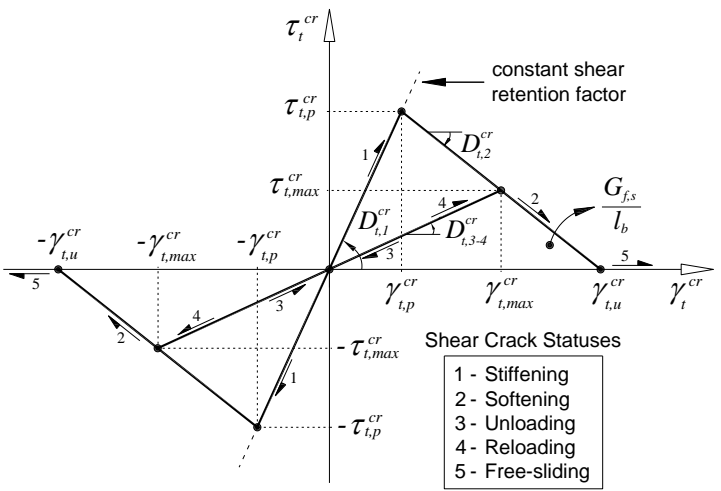

b)

Figure 11: a) Tri-linear crack normal stress vs. crack normal strain diagram to simulate the fracture mode I crack propagation b) Diagram to simulate the relationship between the crack shear stress and the crack shear strain component, and possible shear crack statuses 


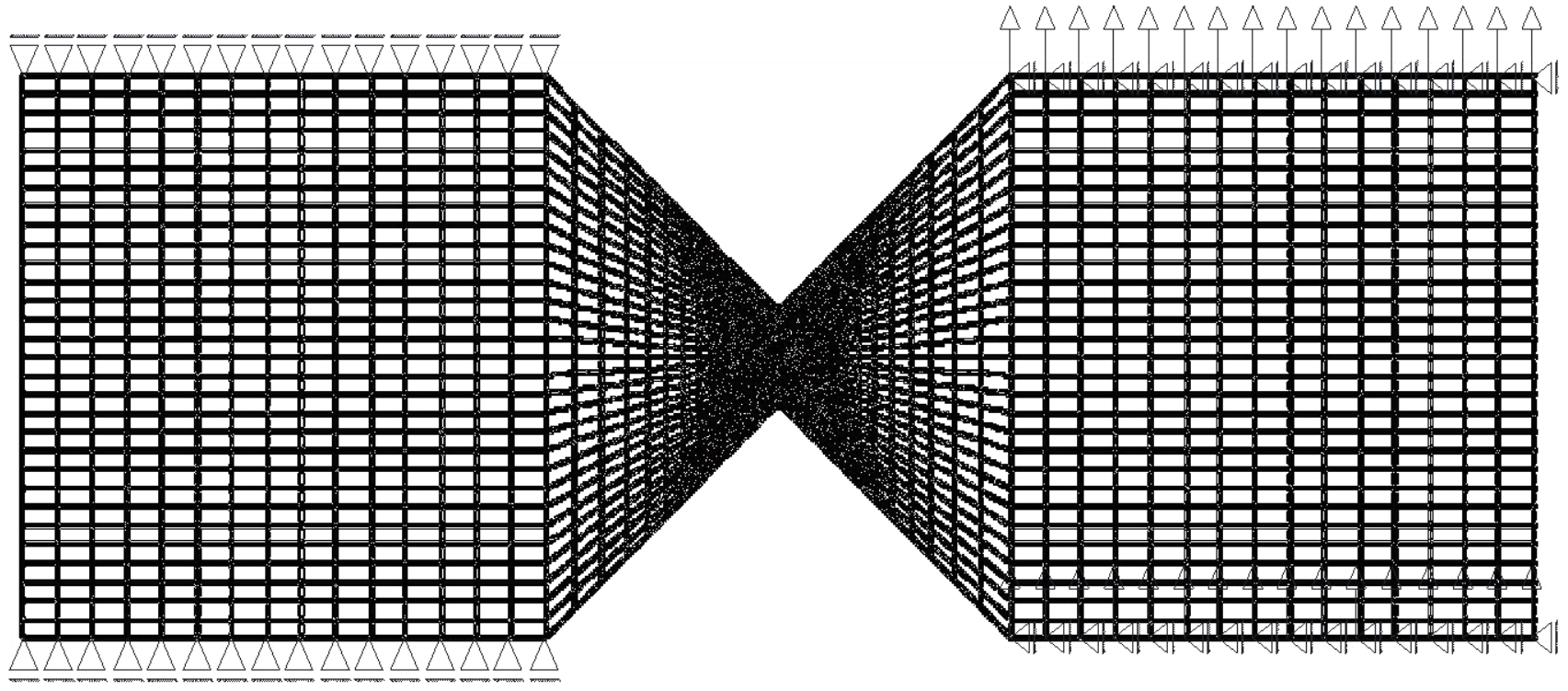

Figure 12: Finite element mesh of the Iosipescu specimen 


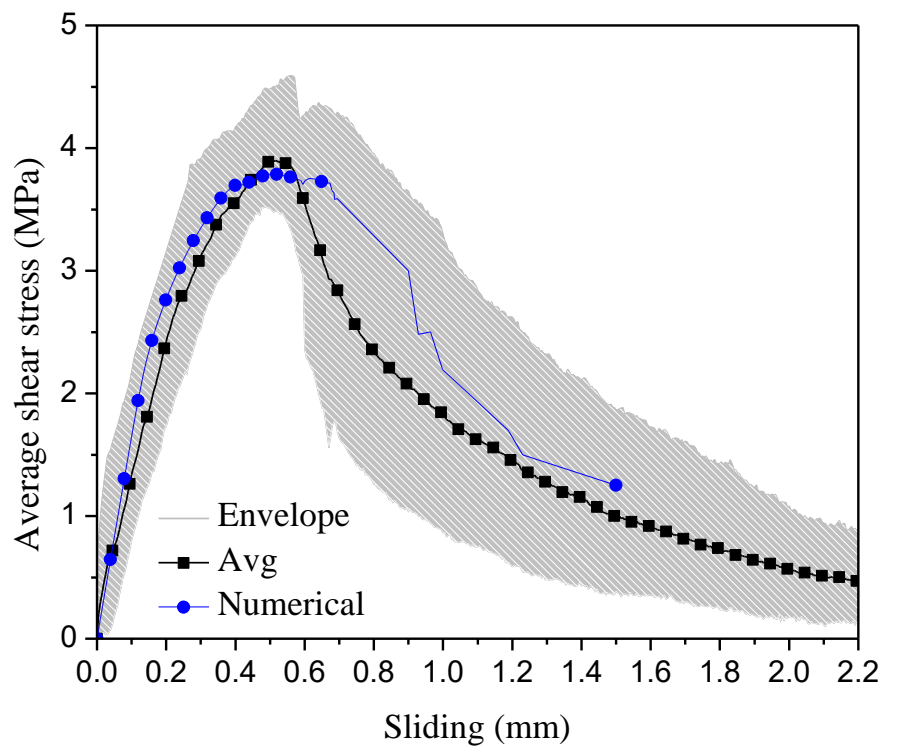

Figure 13: Comparison between experimental and numerical average shear stress versus sliding relationship 


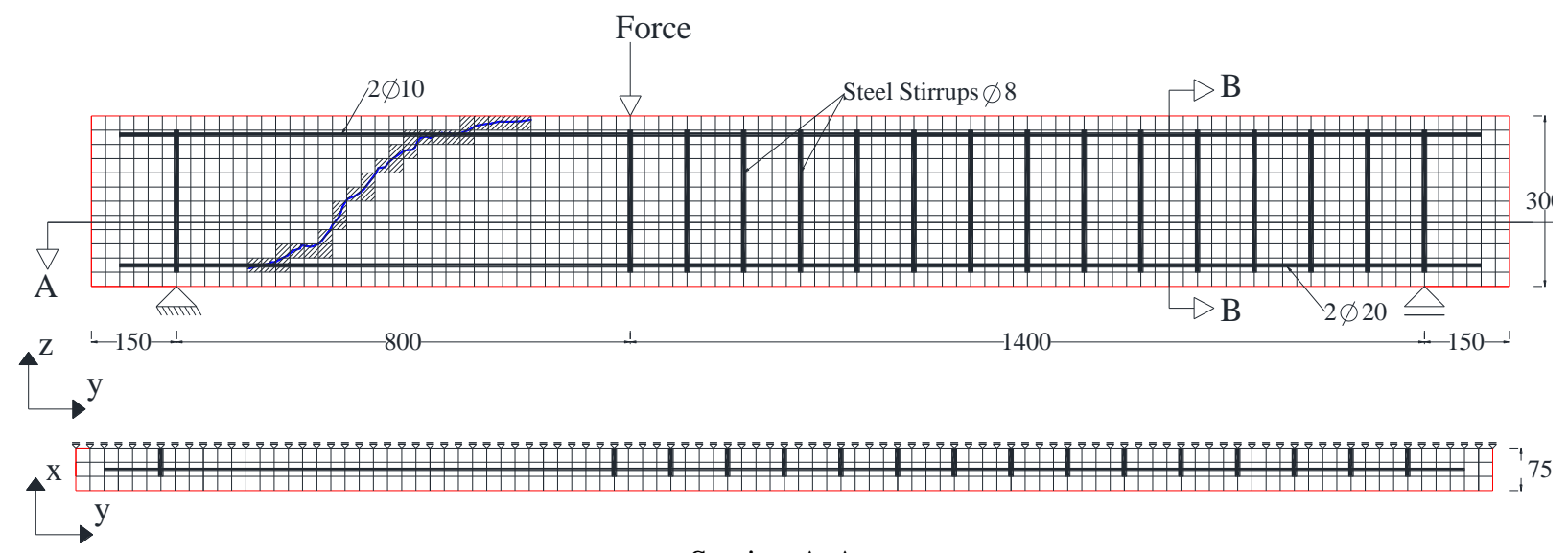

Section A-A

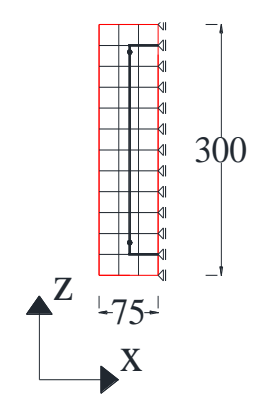

Section B-B

Figure 14: Geometry, mesh and support conditions of the representative rectangular cross section beam of series A (dimensions in $\mathrm{mm}$ ) 

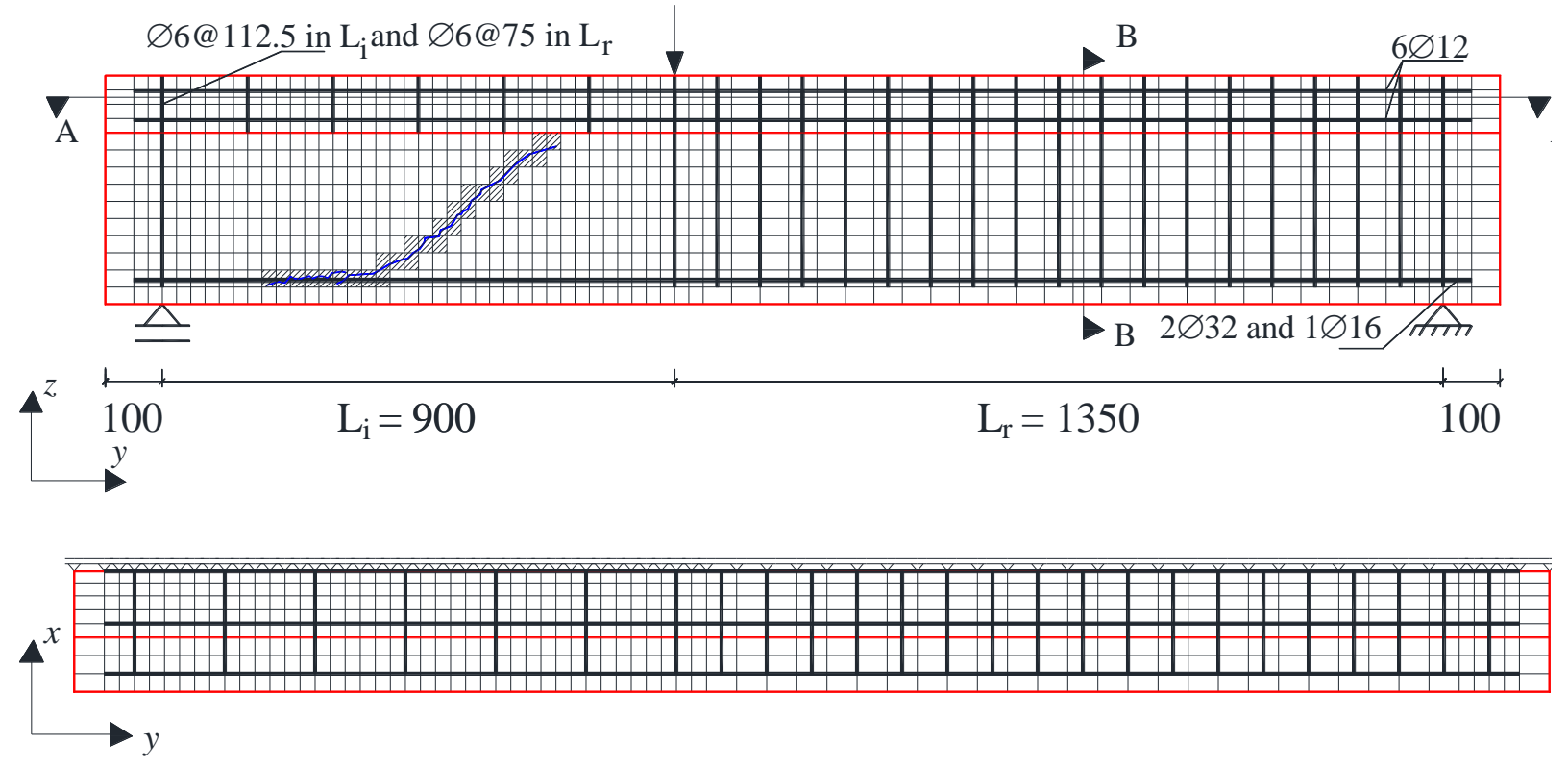

Section A-A

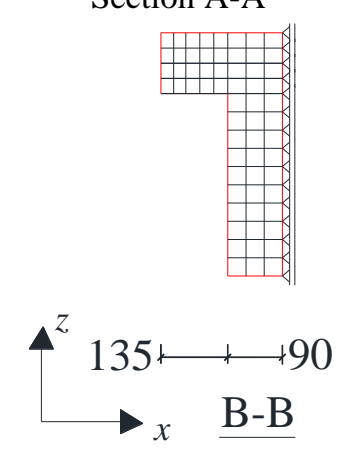

Section B-B

Figure 15: Geometry, mesh and support conditions of the representative T cross section beam of series B (dimensions in $\mathrm{mm}$ ) 


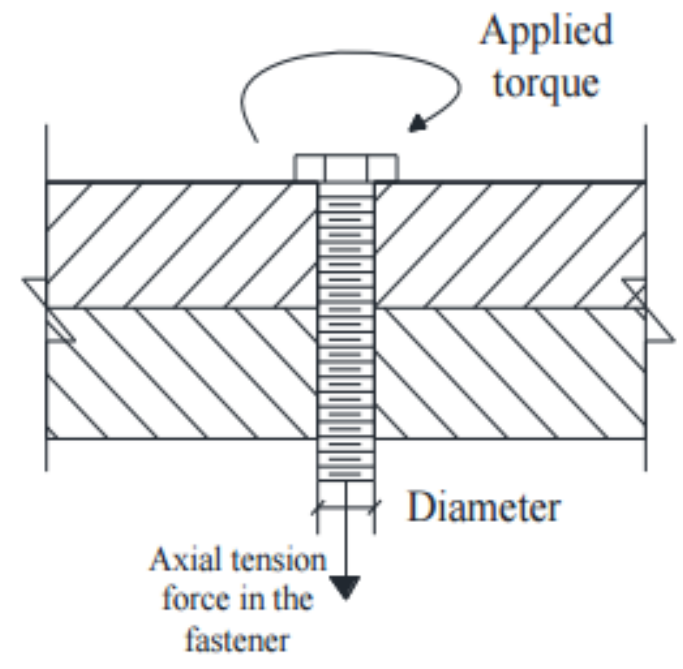

Figure 16: The relation between applied torque to axial tension force fastener 

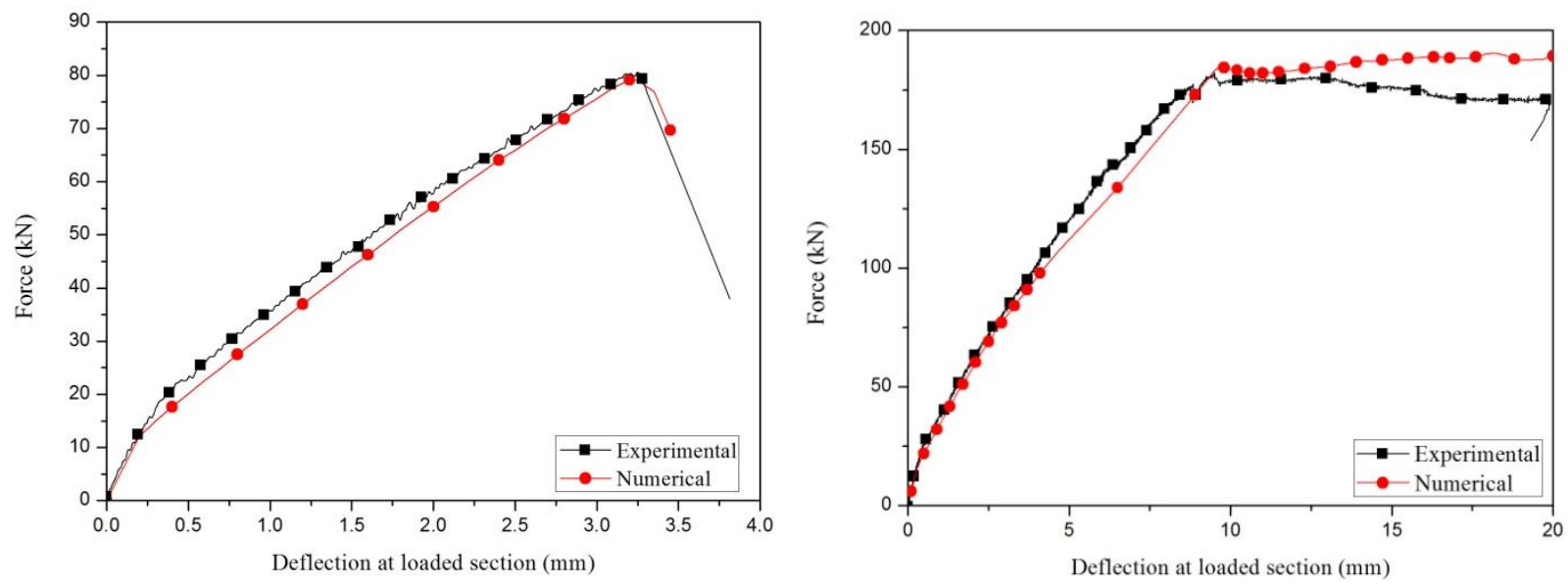

(a) R-C-R

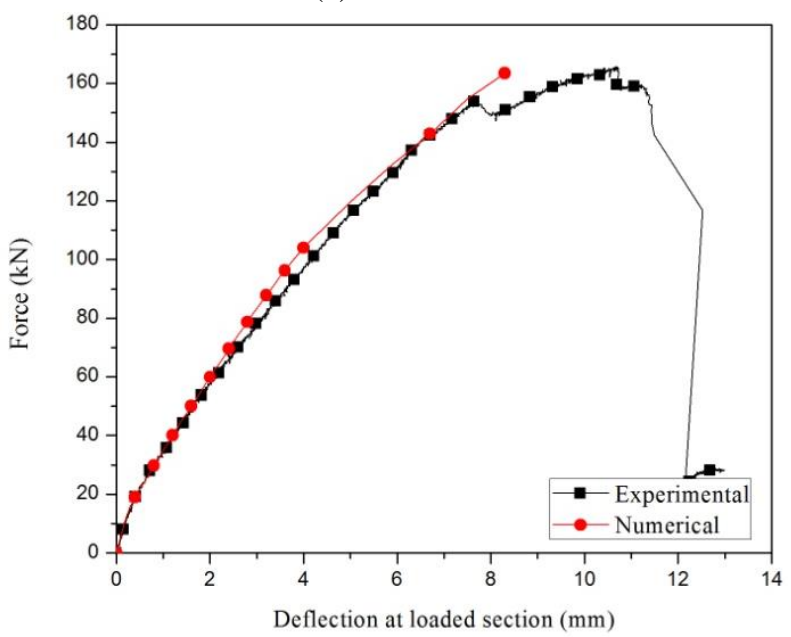

(b) R-7S-R

(c) $\mathrm{R}-3 \mathrm{~L}$

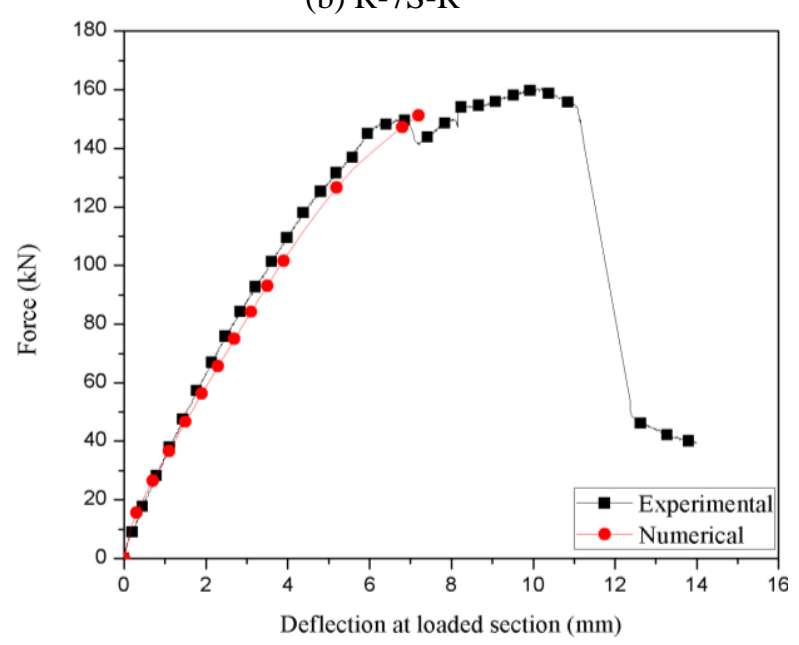

(d) R-D-3L-B

Figure 17: Comparison between experimental and numerical relationships of force vs. deflection at the loaded section of rectangular beams 


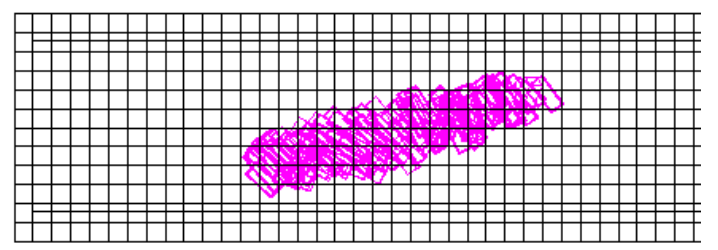

a) R-C-R (Fig. 5a)

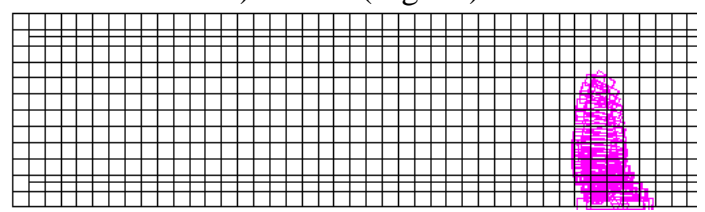

b) R-7S-R (refer to Fig. 5b)

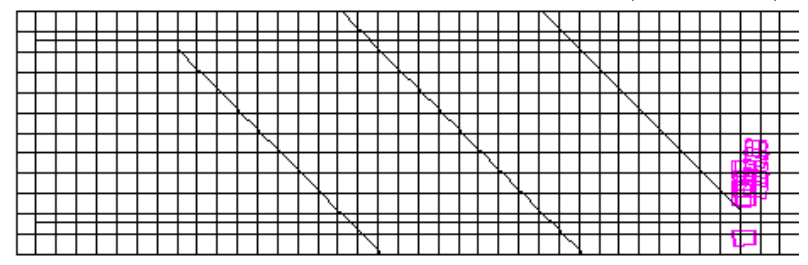

c) R-3L (concrete substrate)

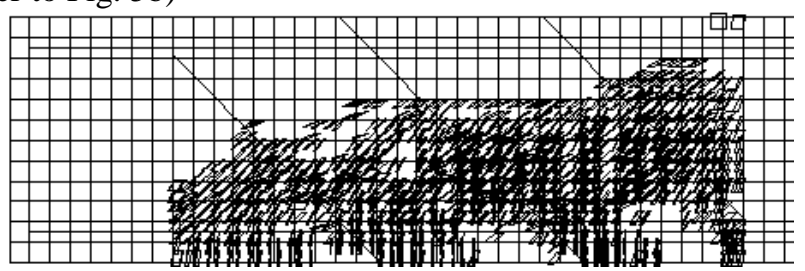

d) R-3L (HCP) (refer to Fig. 5c)

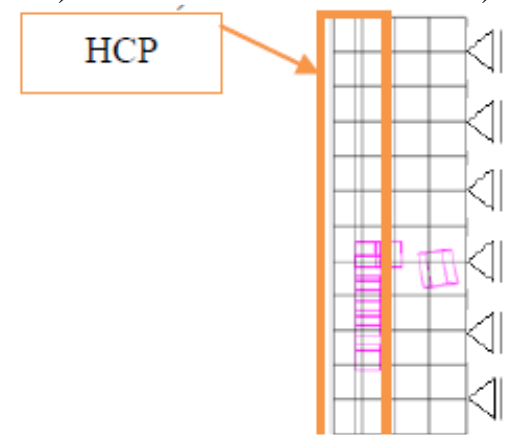

e) R-3L

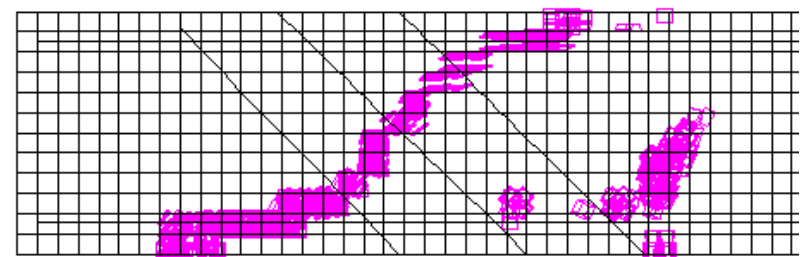

f) R-D-3L-B (concrete substrate)

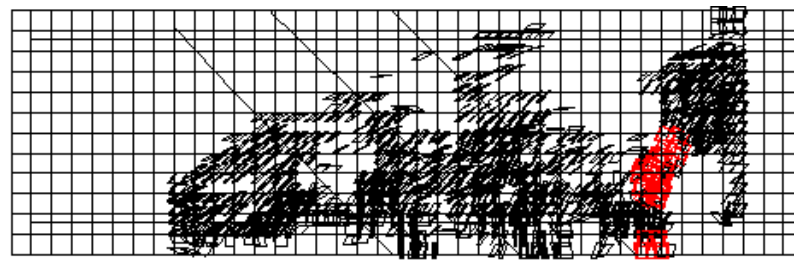

g) R-D-3L-B (HCP) (refer to Fig. 5e)

Figure 18: Crack pattern of the beams of rectangular cross section (in gray color: crack completely open; in black color: crack in the opening process) 

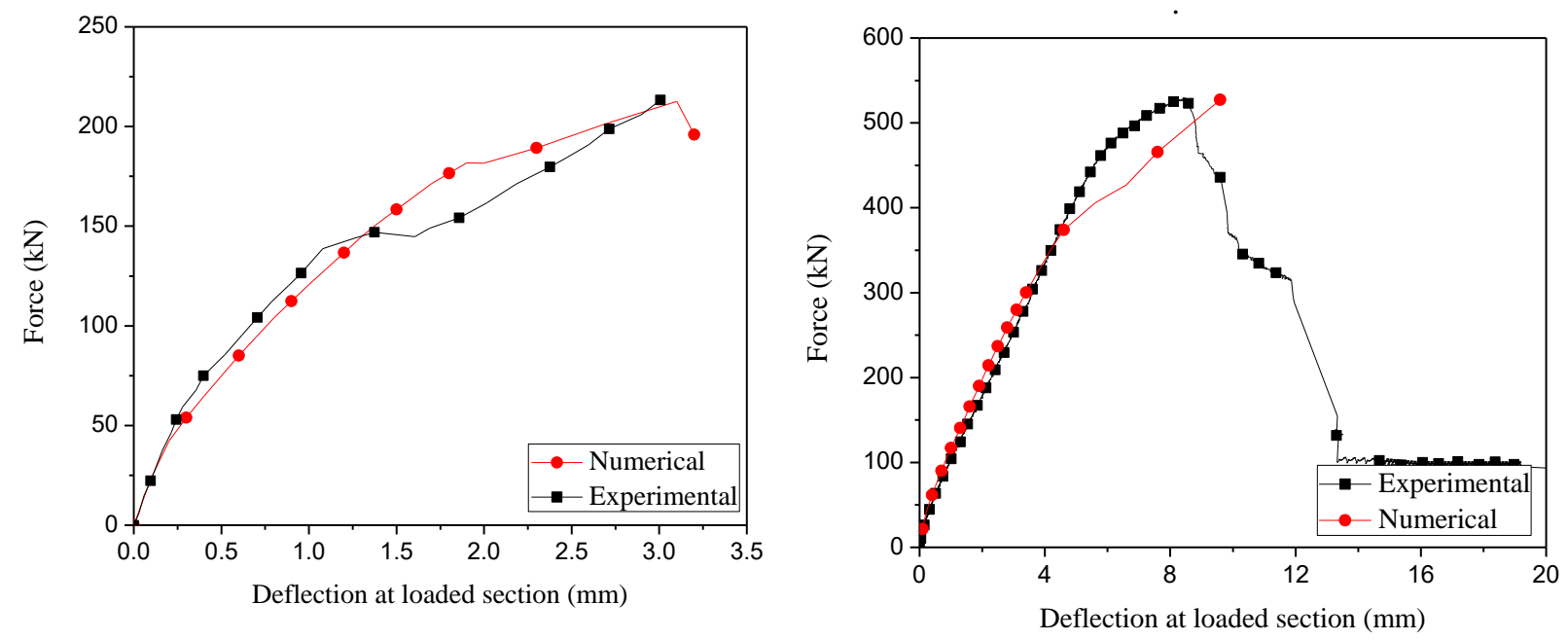

T-C-R
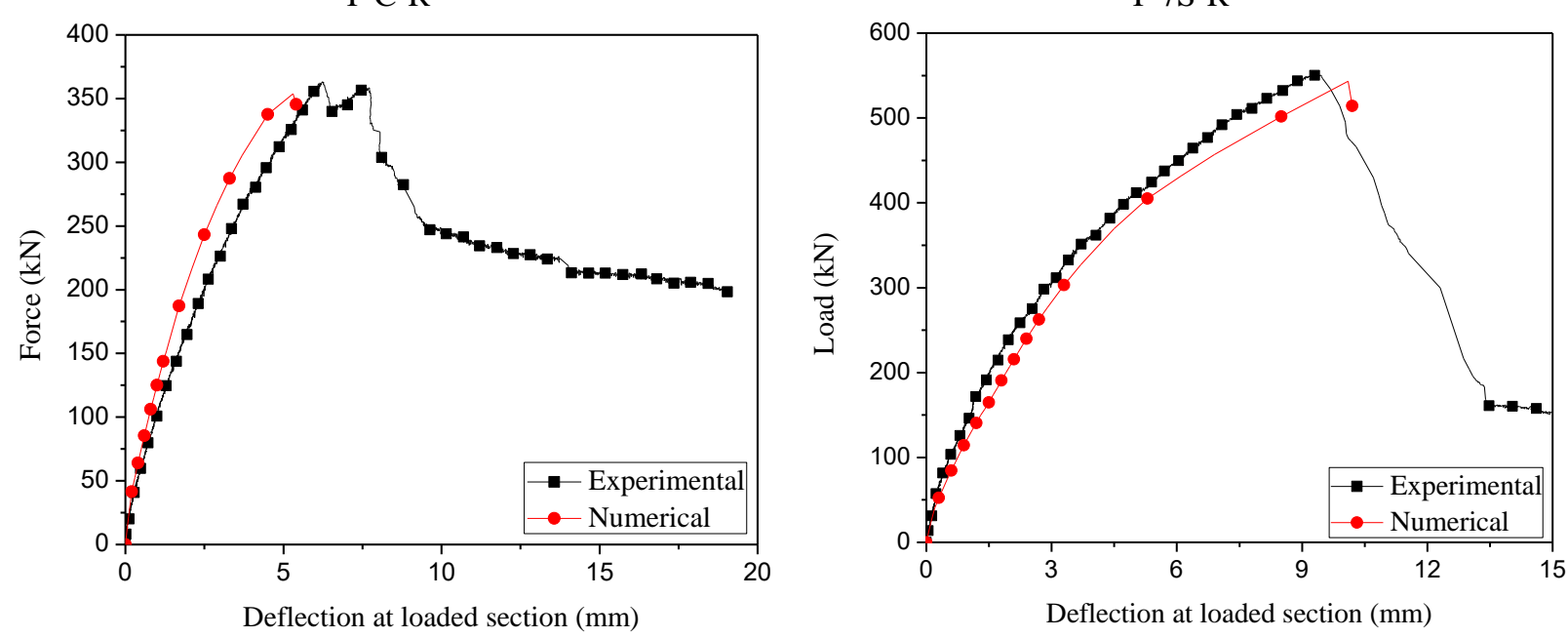

T-5L-B T-5L-BC

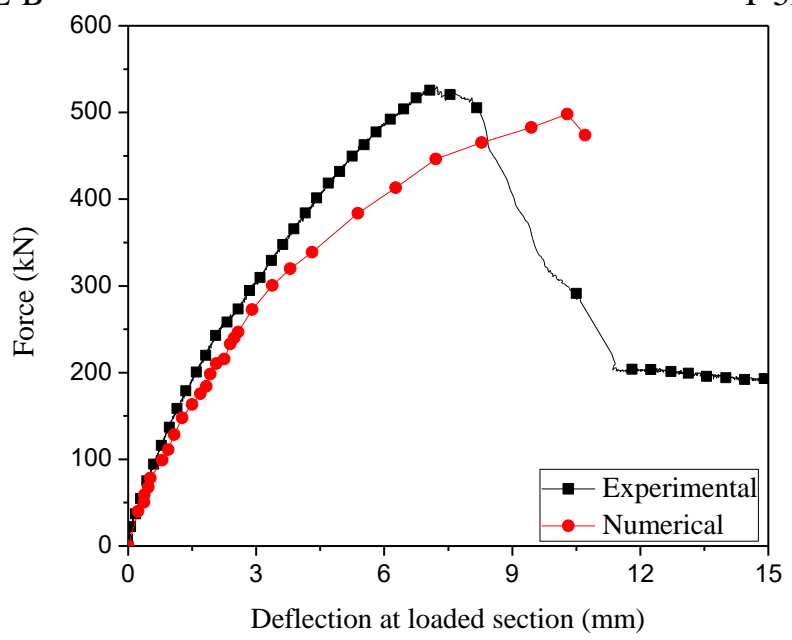

T-D-5L-BC

Figure 19: Comparison between experimental and numerical relationships of force vs. deflection at the loaded section of $\mathrm{T}$ cross section beams 


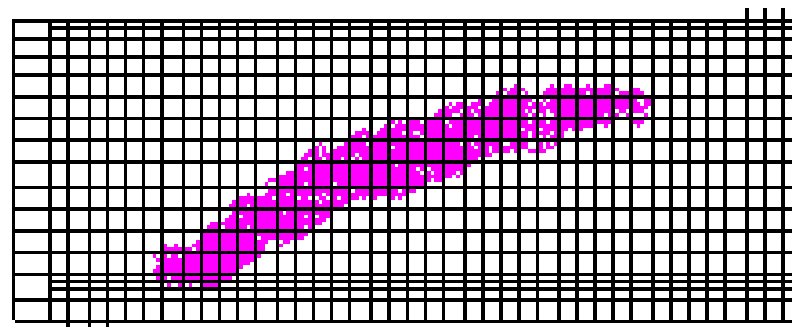

T-C-R (refer to Fig. 7a)

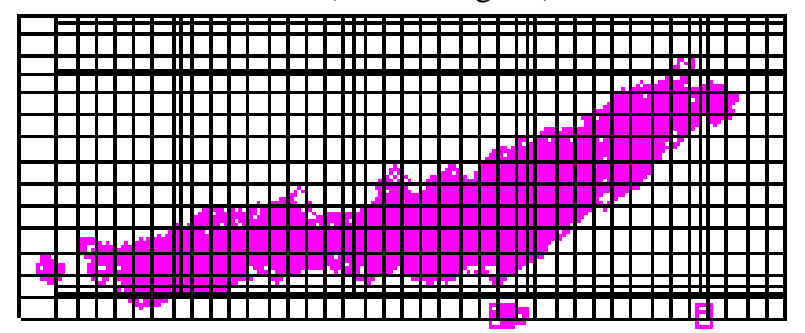

T-7S-R (refer to Fig. 7b)

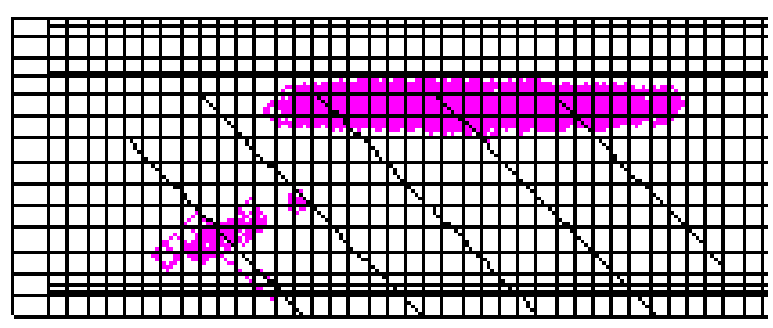

T-5L-B (concrete substrate)

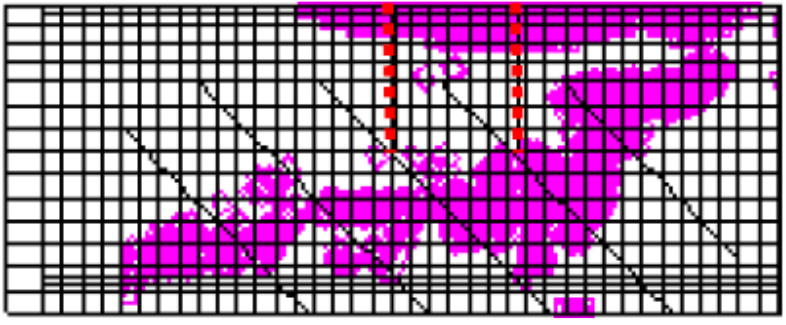

T-5L-BC (concrete substrate)

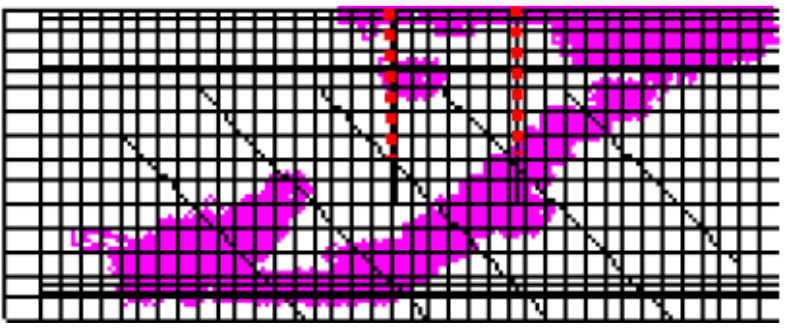

T-D-5L-BC (concrete substrate)

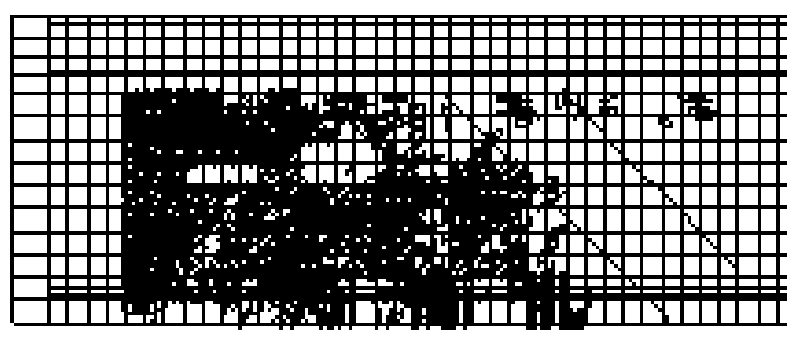

T-5L-B (HCP) (refer to Fig. 7c)

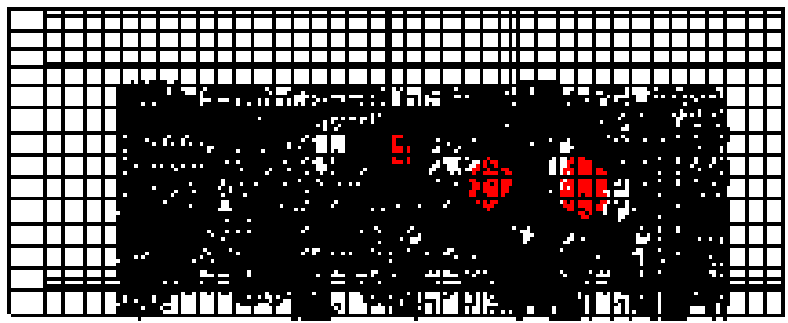

T-5L-BC (HCP) (refer to Fig. 7d)

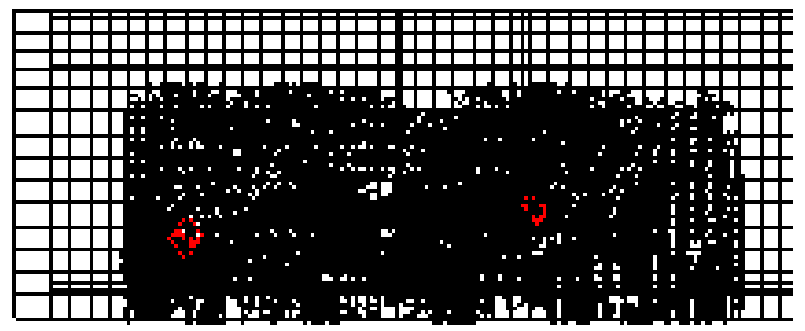

T-D-5L-BC (HCP) (refer to Fig. 7e)

Figure 20: Crack pattern of the beams of $\mathrm{T}$ cross section (in gray color: crack completely open; in black color: crack in the opening process) 


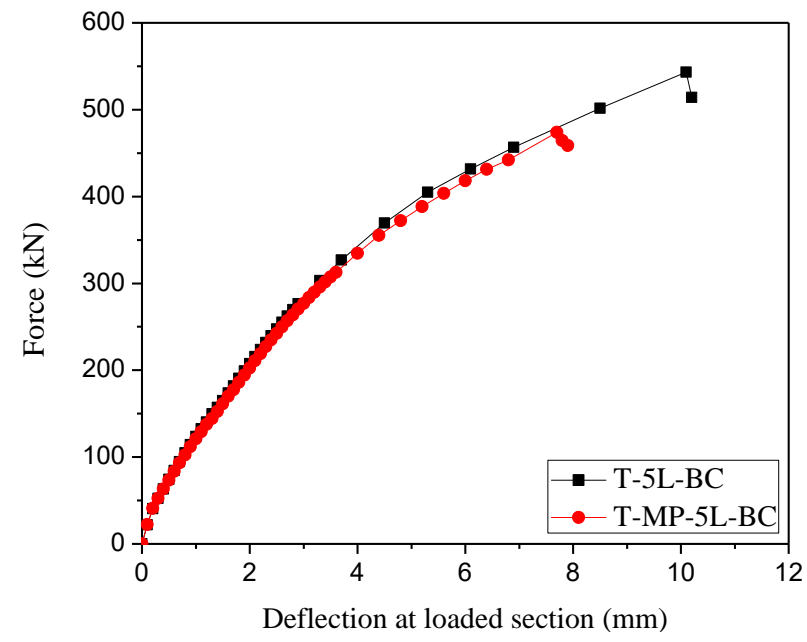

Figure 21: Influence of mortar instead of SHCC on the relationship between the force and the deflection at loaded section 


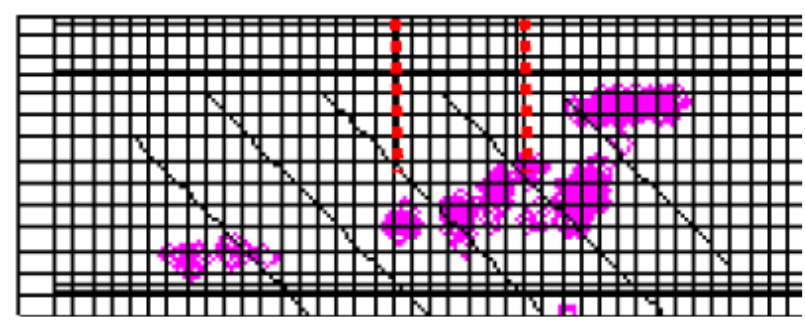

T-5L-BC (concrete substrate)

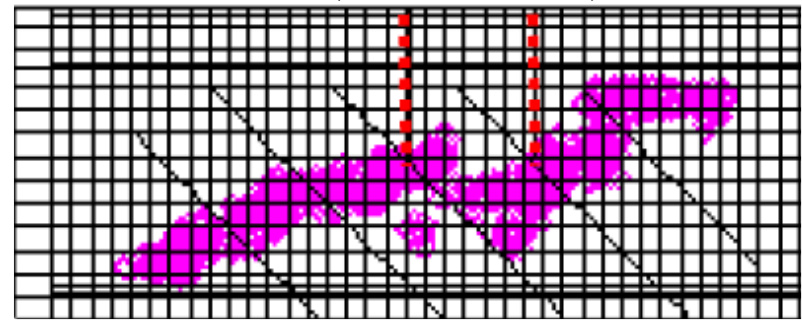

T-MP-5L-BC (concrete substrate)

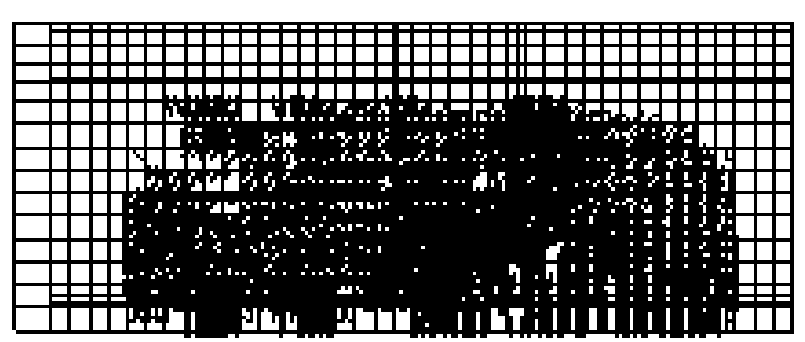

T-5L-BC (HCP)

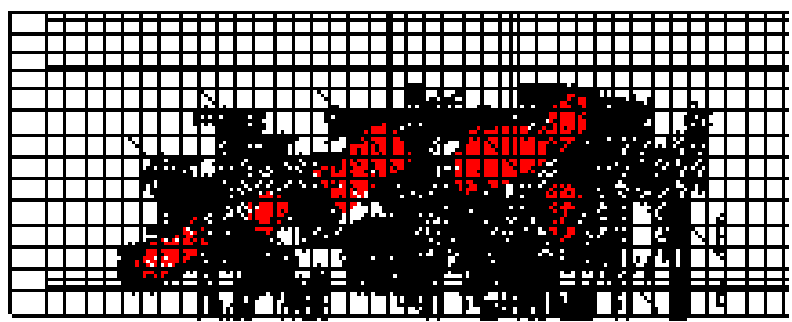

T-MP-5L-BC (Mortar Plate)

Figure 22: Influence of mortar instead of SHCC on the crack patterns at ultimate load of the strengthened beam with mortar plates (in gray color: crack completely open; in black color: crack in the opening process) 


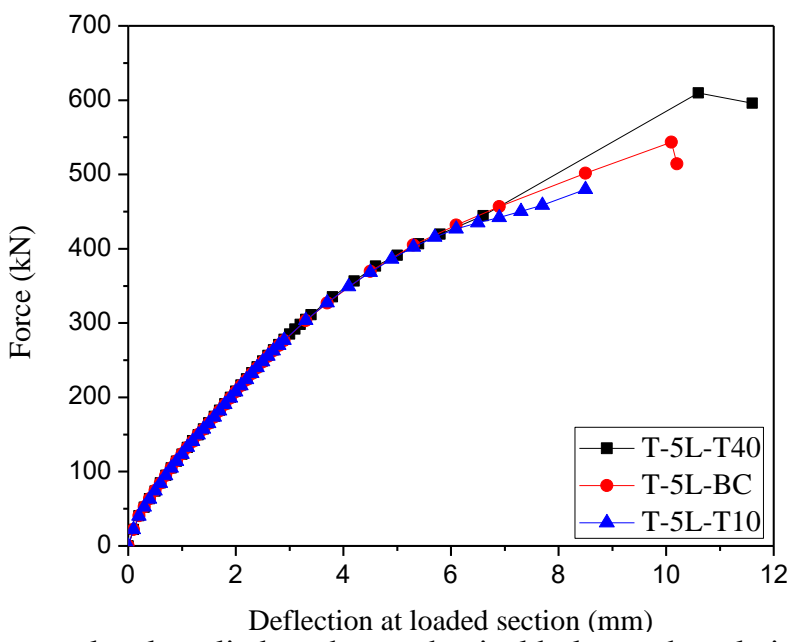

Figure 23: Influence of the torque level applied on the mechanical bolts on the relationship between the force and the deflection at loaded section 


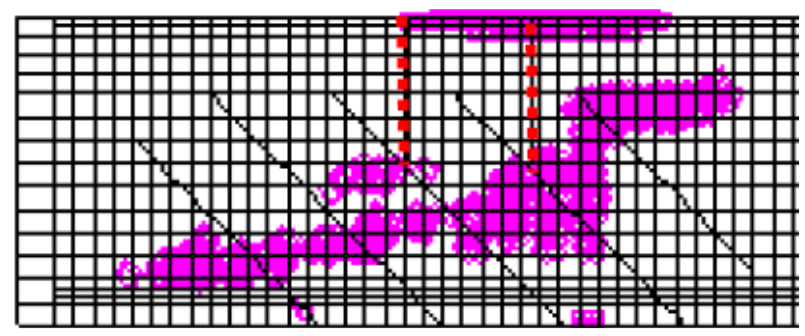

T-5L-T10 (concrete substrate)

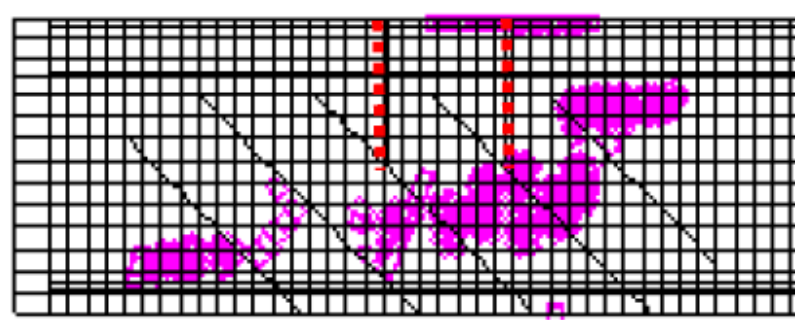

T-5L-BC (concrete substrate)

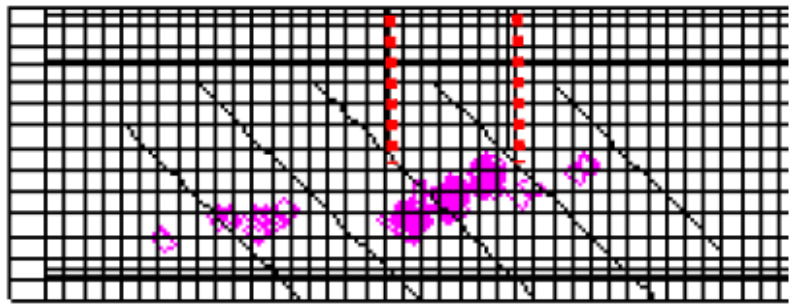

T-5L-T40 (concrete substrate)

Figure 24: Influence of the torque level applied on the mechanical anchors on the crack patterns at the ultimate load of the beams with the lowest torque level (T-5L-T10) (in gray color: crack completely open; in black color: crack in the opening process) 


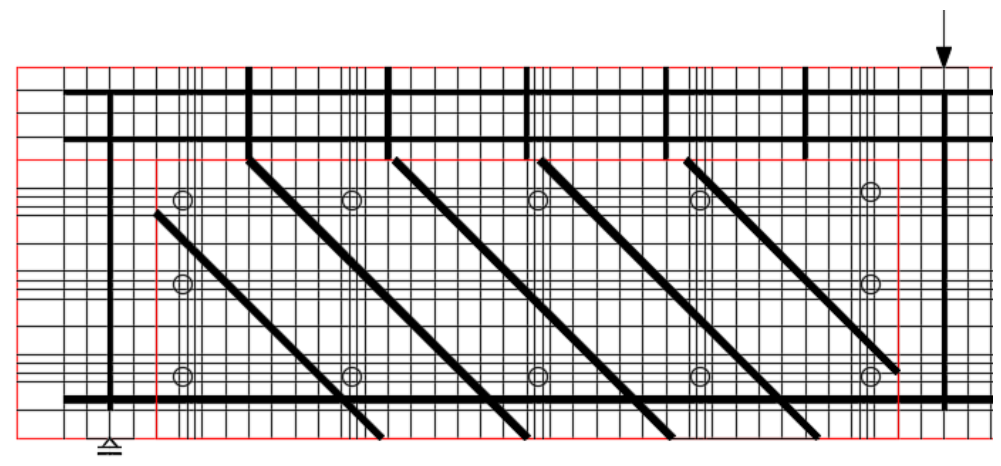

Figure 25: New mesh to simulate the effect of strain gradients on the HCPs around the anchors when perfect bond between HCPs and concrete substrate is not assured 


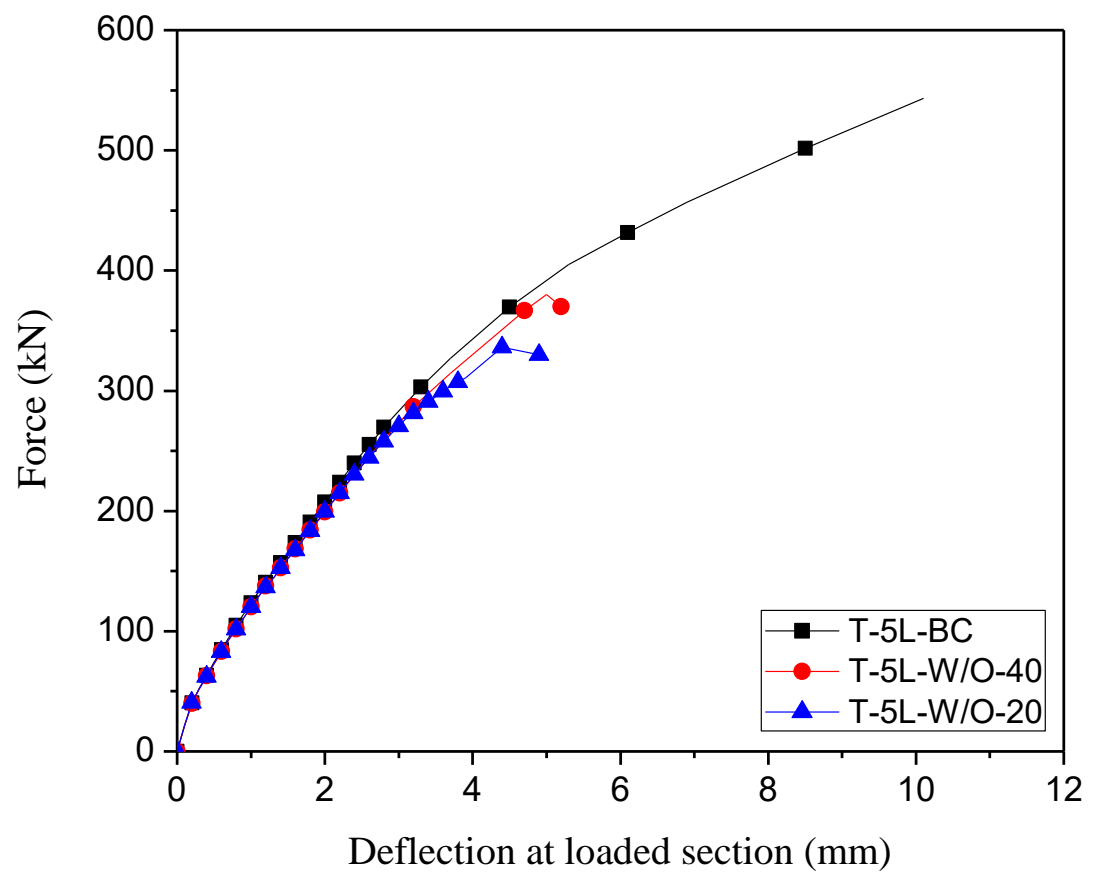

a) Load-deflection

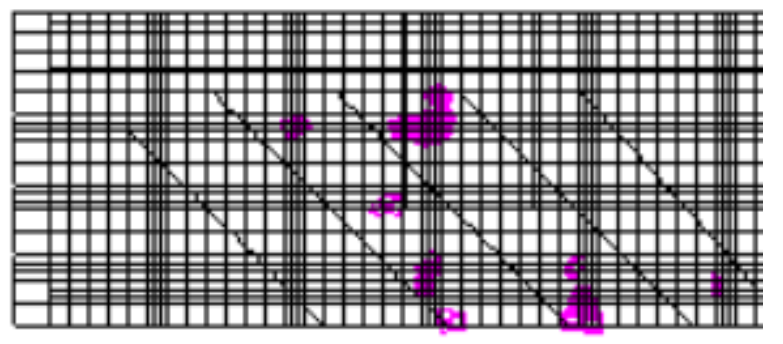

b) Crack pattern of HCPs in T-5L-W/O-20 beam

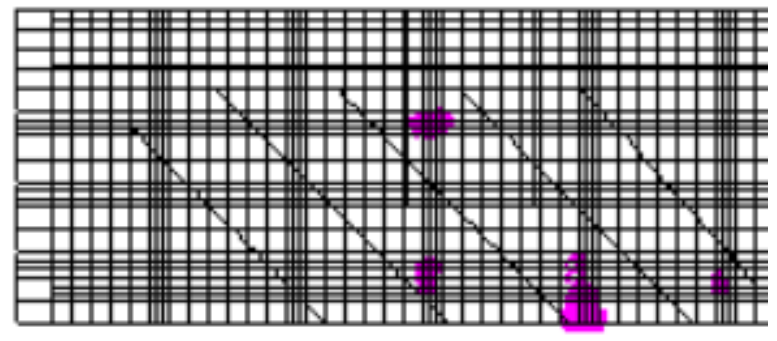

c) Crack pattern of HCPs in T-5L-W/O-40 beam

Figure 26: Effect of strain gradients due to shear deformation of mechanical anchors on load carrying capacity and crack pattern 


\section{LIST OF TABLE CAPTIONS}

Table 1- Shear strengthening/reinforcement in the monitored shear span of the tested beams

Table 2: Material Properties

Table 3 - Values of the parameters of the steel constitutive model

Table 4 - Relevant results in terms of load and deflection capacity

Table 5 - Values of the parameters of the SHCC constitutive model

Table 6 - Values of the parameters of the concrete constitutive model 
Table 1-Shear strengthening/reinforcement in the monitored shear span of the tested beams

\begin{tabular}{|c|c|c|c|c|c|c|}
\hline & $\begin{array}{c}\text { Beam } \\
\text { designation }\end{array}$ & $\begin{array}{c}\text { Shear } \\
\text { strengthening/reinforcement } \\
\text { configuration }\end{array}$ & Quantity & $\begin{array}{l}\text { Connection } \\
\text { of the HCP } \\
\text { to substrate }\end{array}$ & $\begin{array}{l}\text { connector } \\
\text { of the web } \\
\text {-flange }\end{array}$ & $\begin{array}{c}\text { Spacing, } \\
s_{f} \\
(\mathrm{~mm})\end{array}$ \\
\hline \multirow{4}{*}{ 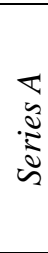 } & $R-C-R$ & - & - & - & - & - \\
\hline & $R-3 L$ & \multirow{2}{*}{$\begin{array}{l}\text { HCPs }(20 \mathrm{~mm} \text { thickness of } \\
\text { SHCC reinforced with } \\
\text { CFRP laminates of } 1.4 \times 10 \\
\mathrm{~mm}^{2} \text { cross section) }\end{array}$} & \multirow[b]{2}{*}{$\begin{array}{l}2 \times 3 \text { CFRP } \\
\text { laminates }\end{array}$} & Adhesive & & 250 \\
\hline & $R-D-3 L-B$ & & & $\begin{array}{c}\text { Adhesive \& } \\
\text { mechanical } \\
\text { anchors }\end{array}$ & & 150 \\
\hline & $R-7 S-R$ & Steel stirrups & $\phi 8$ & & - & 100 \\
\hline \multirow{5}{*}{ 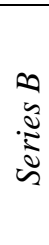 } & $T-C-R$ & - & - & - & - & - \\
\hline & $T-5 L-B$ & \multirow{3}{*}{$\begin{array}{l}\text { HCPs }(20 \mathrm{~mm} \text { thickness of } \\
\text { SHCC reinforced with } \\
\text { CFRP laminates of } 1.4 \times 10 \\
\left.\mathrm{~mm}^{2} \text { cross section }\right)\end{array}$} & \multirow{3}{*}{$\begin{array}{l}2 \times 5 \text { CFRP } \\
\text { laminates }\end{array}$} & \multirow{3}{*}{$\begin{array}{c}\text { Adhesive \& } \\
\text { mechanical } \\
\text { anchors }\end{array}$} & - & \multirow{3}{*}{157} \\
\hline & $T-5 L-B C$ & & & & 4 steel hars & \\
\hline & $T-D-5 L-B C$ & & & & $\phi 10$ & \\
\hline & $T-7 S-R$ & Steel stirrups & $\phi 6$ & & & 112.5 \\
\hline
\end{tabular}


Table 2: Material Properties

\begin{tabular}{ccccc}
\hline Property & Concrete & CFRP & $\begin{array}{c}\text { Epoxy } \\
\text { adhesive }\end{array}$ & SHCC \\
\hline $\begin{array}{c}\text { Compressive strength } \\
(\mathrm{MPa})\end{array}$ & 33.0 & - & & 32.0 \\
\hline $\begin{array}{c}\text { Tensile strength }(\mathrm{MPa}) \\
\text { Elasticity modulus }(\mathrm{GPa})\end{array}$ & - & 2620 & 18 & 3.5 \\
\hline Maximum tensile strain $(\%)$ & - & 150 & 6.8 & 18 \\
\hline $\begin{array}{c}\text { Tensile stress at crack } \\
\text { initiation }(\mathrm{MPa})\end{array}$ & - & - & & 1.6 \\
\hline
\end{tabular}


Table 3 - Values of the parameters of the steel constitutive model

\begin{tabular}{|c|c|c|c|c|c|c|c|}
\hline Property & $\phi 6$ & $\phi 8$ & $\phi 10$ & $\phi 12$ & $\phi 16$ & $\phi 20$ & $\phi 32$ \\
\hline$f_{\text {yield }}\left(\mathrm{N} / \mathrm{mm}^{2}\right)$ & 500 & 545 & 530 & 490 & 470 & 575 & 625 \\
\hline$f_{\text {ultimate }}\left(\mathrm{N} / \mathrm{mm}^{2}\right)$ & 595 & 610 & 625 & 590 & 565 & 640 & 905 \\
\hline
\end{tabular}


Table 4 - Relevant results in terms of load and deflection capacity

\begin{tabular}{|c|c|c|c|c|c|}
\hline & $\begin{array}{c}\text { Beam } \\
\text { designation }\end{array}$ & $\begin{array}{l}F_{\text {max }} \\
(k N)\end{array}$ & $\begin{array}{c}\text { Deflection } \\
\text { at loaded } \\
\text { section } \\
(\mathrm{mm})\end{array}$ & $\begin{array}{c}\text { Shear } \\
\text { resistance } \\
(k N)\end{array}$ & $\begin{array}{c}\frac{F_{\max }}{F_{\max }^{7 S-R}} \\
(\%)\end{array}$ \\
\hline \multirow{4}{*}{ 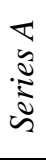 } & $R-C-R$ & 81 & 3.3 & 51 & 45 \\
\hline & $R-3 L$ & 166 & 12.5 & 105 & 91 \\
\hline & $R-D-3 L-B$ & 161 & 10.1 & 103 & 88 \\
\hline & $R-7 S-R$ & 182 & 19.9 & 116 & 100 \\
\hline \multirow{5}{*}{$\begin{array}{l}n \\
\frac{2}{2} \\
\frac{1}{2}\end{array}$} & $T-C-R$ & 214 & 3.0 & 128 & 40 \\
\hline & $T-5 L-B$ & 364 & 6.3 & 218 & 68 \\
\hline & $T-5 L-B C$ & 552 & 9.4 & 331 & 104 \\
\hline & $T-D-5 L-B C$ & 530 & 7.2 & 318 & 100 \\
\hline & $T-7 S-R$ & 530 & 8.4 & 318 & 100 \\
\hline
\end{tabular}


Table 5 - Values of the parameters of the SHCC constitutive model Parameters Values

\begin{tabular}{lc}
\hline$v_{c}$ & 0.15 \\
\hline$E_{c}\left(N / \mathrm{mm}^{2}\right)$ & 14000 \\
\hline$f_{c}\left(N / \mathrm{mm}^{2}\right)$ & 32.0 \\
\hline$f_{c t}\left(N / \mathrm{mm}^{2}\right)$ & 2.35 \\
\hline$G_{f}(N / \mathrm{mm})$ & 3.5 \\
\hline$\xi_{1}$ & 0.11 \\
\hline$\alpha_{1}$ & 1.27 \\
\hline$\xi_{2}$ & 0.54 \\
\hline$\alpha_{2}$ & 0.11 \\
\hline$\tau_{t, p}^{c r}\left(N / \mathrm{mm}^{2}\right)$ & 1.0 \\
\hline$G_{f, s}\left(N / \mathrm{mm}^{2}\right)$ & 0.5 \\
\hline$\beta$ & 0.15 \\
\hline
\end{tabular}


Table 6 - Values of the parameters of the concrete constitutive model

\begin{tabular}{lc}
\hline Parameters & Values \\
\hline$v_{c}$ & 0.19 \\
\hline$E_{c}\left(N / \mathrm{mm}^{2}\right)$ & 31381 \\
\hline$f_{c}\left(N / \mathrm{mm}^{2}\right)$ & 33.0 \\
\hline$f_{c t}\left(N / \mathrm{mm}^{2}\right)$ & 2.1 \\
\hline$G_{f}(N / \mathrm{mm})$ & 0.08 \\
\hline$\xi_{1}$ & 0.005 \\
\hline$\alpha_{1}$ & 0.3 \\
\hline$\xi_{2}$ & 0.1 \\
\hline$\alpha_{2}$ & 0.3 \\
\hline$\tau_{t, p}^{c r}\left(N / \mathrm{mm}^{2}\right)$ & 1.1 \\
\hline$G_{f, s}\left(N / \mathrm{mm}^{2}\right)$ & 0.045 \\
\hline$\beta$ & 0.6 \\
\hline
\end{tabular}

